Fatigue crack growth mechanisms in powder metallurgy Ni-based superalloys - A review

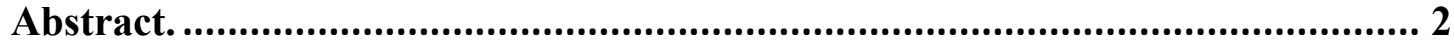

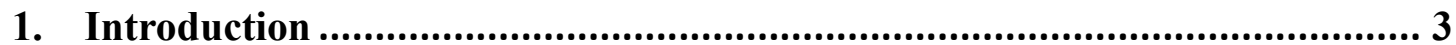

2. Short fatigue crack growth mechanisms ................................................... 5

2.1 Characteristics of short fatigue crack growth and research

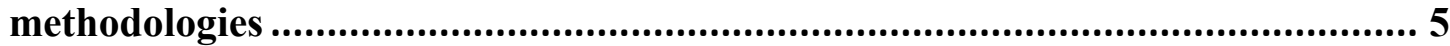

2.2 Effects of microstructure ........................................................... 8

2.2.1 Effects of grain size ............................................................. 8

2.2.2 Effects of grain orientation ...................................................10

2.2.3 Effects of $\gamma^{\prime}$ precipitates....................................................12

2.2.4 Effects of non-metallic inclusions............................................14

2.3 Extrinsic effects on short fatigue crack growth ...............................15

3. Long fatigue crack growth mechanisms ...................................................17

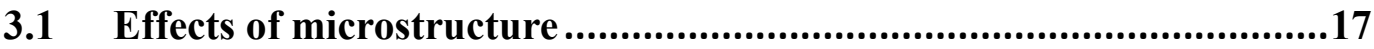

3.1.1 Effects of grain size .........................................................17

3.1.2 Effects of $\gamma^{\prime}$ precipitates .....................................................19

3.1.3 Effects of grain boundary character and precipitates...............25

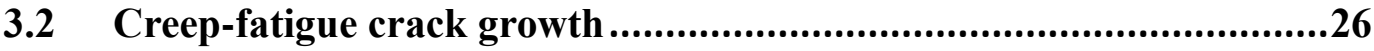

3.3 Effects of environmental damage ................................................29

3.3.1 Environmental damage enhanced fatigue crack growth...............29

3.3.2 Threshold fatigue crack growth behaviours ..................................33

3.3.3 Characterisation of deformation at the crack tip ..........................34

4. Perspectives and concluding remarks ......................................................36

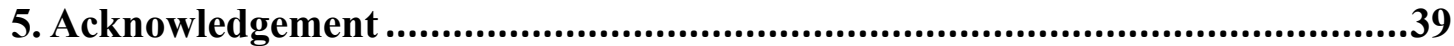

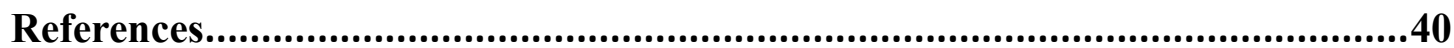




\title{
Fatigue crack growth mechanisms in powder metallurgy Ni-based
}

\section{superalloys-A review}

\author{
R. Jiang ${ }^{1,2,3 *}$, Y. D. Song ${ }^{1,2}$, P. A. Reed ${ }^{3 *}$ \\ ${ }^{1}$ Key Laboratory of Aero-engine Thermal Environment and Structure, Ministry of Industry \\ and Information Technology, Nanjing University of Aeronautics and Astronautics, Nanjing,
} 210016, PR China

${ }^{2}$ College of Energy and Power Engineering, Nanjing University of Aeronautics and Astronautics, Nanjing, 210016, China

3 Materials Research Group, Department of Mechanical Engineering, University of Southampton, Highfield, Southampton, SO17 1BJ, UK

*Corresponding author. Email: rjiang@nuaa.edu.cn; p.a.reed@soton.ac.uk

Abstract: Powder metallurgy (PM) Ni-based superalloys are widely used for aeroengine turbine disc applications due to their excellent mechanical properties and good corrosion resistance at elevated temperatures. Understanding the fatigue crack growth (FCG) mechanisms of PM Ni-based superalloys is important for both disc alloy development and life prediction of disc components in these advanced aeroengines where damage tolerance design prevails. FCG in PM Ni-based superalloys is a complicated function of microstructure, temperature, loading conditions and environment and is usually a consequence of the synergistic effects of fatigue, creep and environmental damage. In this review, the mechanisms controlled by microstructural features including grain size, grain misorientation, $\gamma^{\prime}$ size and distribution on short and long FCG behaviour in PM Ni-based superalloys are discussed. The contribution of creep and environmental damage to FCG has been critically assessed. The competing effects of mechanical damage (i.e. fatigue and creep) and environmental damage at the crack tip are microstructure-sensitive, and usually results in transition between transgranular, mixed-trans-intergranular and intergranular FCG depending on the contribution of environmental damage to FCG processes.

Keywords: PM Ni-based superalloys; microstructures; fatigue crack growth; creep; environmental damage; 


\section{Introduction}

Polycrystalline Ni-based superalloys, which mainly consist of $\gamma$ phase and the strengthening $\gamma^{\prime}$ phase, i.e. $(\mathrm{Ni} 3(\mathrm{Al}, \mathrm{Ti}))$, are widely used for turbine disc application in aeroengines due to their excellent mechanical properties, fatigue and creep resistance at high temperature, good phase stability, in combination with superior corrosion and oxidation resistance [1-3]. With the development of more advanced aeroengines, powder metallurgy (PM) Ni-based superalloys are increasingly used in turbine discs. Compared with conventional cast and wrought Ni-based superalloys, PM Ni-based superalloys can effectively eliminate solidification segregation and thereby can allow increases in the alloying levels to further improve the overall mechanical properties [1]. This is necessary to meet the requirement of increased turbine inlet temperatures in more advanced aeroengines with high thrust-to-weight ratios. Through more than half century's development, the working limit temperature has been increased from $650^{\circ} \mathrm{C}$ for the first generation of PM Ni-based superalloys which are characterised by their high strength at elevated temperatures, to $750^{\circ} \mathrm{C}$ or even higher for third and fourth generation PM Ni-based superalloys which are characterised by their excellent high temperature strength and exceptional fatigue crack growth (FCG) resistance [1, 4-7]. Development of the creep resistance of PM Ni-based superalloys is shown in Fig. 1 and their compositions are presented in Table 1.

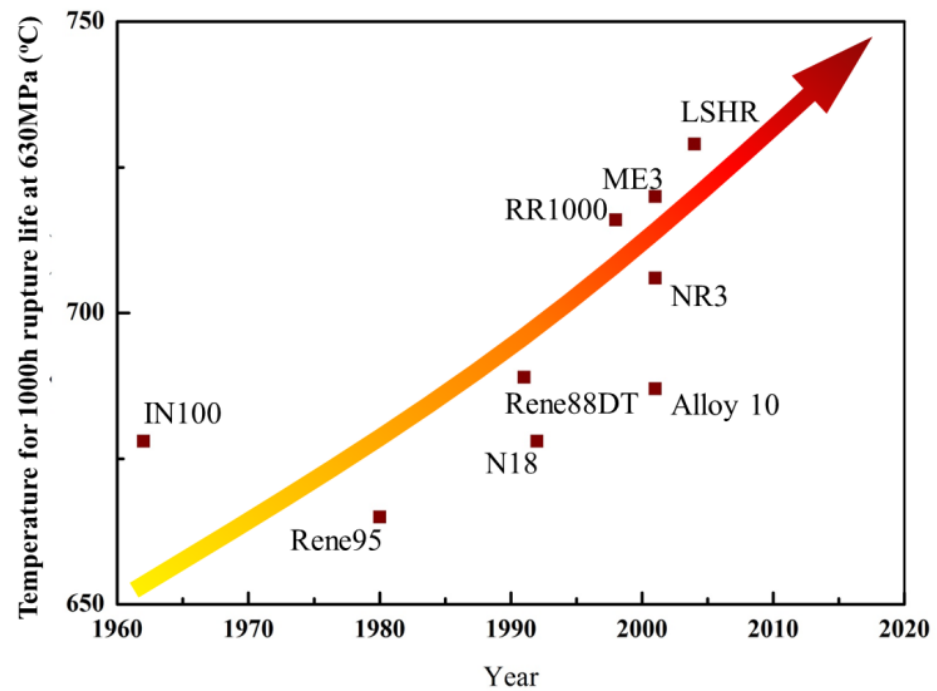

Fig. 1 Development of the creep resistance of PM Ni-based superalloys in turbine disc applications. 
Table 1 Nominal Composition (wt.\%) of PM Ni-based superalloys

\begin{tabular}{|c|c|c|c|c|c|c|c|c|c|c|c|c|c|}
\hline & $\mathrm{Cr}$ & Co & Mo & $\mathbf{W}$ & $\mathbf{N b}$ & Al & $\mathbf{T i}$ & $\mathbf{T a}$ & Hf & C & B & $\mathbf{Z r}$ & $\mathbf{N i}$ \\
\hline Rene95 & 14.0 & 8.0 & 3.5 & 3.5 & 3.5 & 3.5 & 2.5 & - & - & 0.15 & 0.010 & 0.05 & Bal. \\
\hline MERL-76 & 12.4 & 18.6 & 3.3 & - & 1.4 & 0.2 & 0.3 & - & 0.35 & 0.050 & 0.03 & 0.06 & Bal. \\
\hline FGH4095 & 12.69 & 8.55 & 3.58 & 3.36 & 3.45 & 3.46 & 2.69 & $<0.02$ & & 0.06 & 0.01 & 0.05 & Bal. \\
\hline Udimet720Li & 16.0 & 15.0 & 3.0 & 1.25 & - & 2.5 & 5.0 & - & - & 0.025 & 0.018 & 0.05 & Bal. \\
\hline Rene88DT & 16.0 & 13.0 & 4.0 & 4.0 & 0.7 & 2.1 & 3.7 & - & - & 0.03 & 0.015 & 0.03 & Bal. \\
\hline N18 & 11.5 & 15.7 & 6.5 & 0.6 & - & 4.35 & 4.35 & - & 0.45 & 0.015 & 0.015 & 0.03 & Bal. \\
\hline FGH4096 & 16.0 & 13.0 & 4.0 & 4.0 & 0.7 & 2.1 & 3.7 & $<0.02$ & - & 0.035 & 0.011 & 0.033 & Bal. \\
\hline FGH4097 & 9.02 & 15.69 & 3.76 & 4.96 & 2.59 & 4.91 & 1.74 & - & 0.3 & 0.045 & 0.012 & 0.017 & Bal. \\
\hline RR1000 & 15.0 & 18.5 & 5.0 & - & 1.1 & 3.0 & 3.6 & 2.0 & 0.5 & 0.027 & 0.015 & 0.06 & Bal. \\
\hline ME3 & 13.1 & 18.2 & 3.8 & 1.9 & 1.4 & 3.5 & 3.5 & 2.7 & - & 0.03 & 0.03 & 0.05 & Bal. \\
\hline Alloy10 & 11.5 & 15 & 2.3 & 5.9 & 1.7 & 3.8 & 3.9 & 0.75 & - & 0.030 & 0.02 & 0.05 & Bal. \\
\hline LSHR & 12.5 & 20.7 & 2.7 & 4.3 & 1.5 & 3.5 & 3.5 & 1.6 & - & 0.03 & 0.03 & 0.05 & Bal \\
\hline NR3 & 12.5 & 14.9 & 3.55 & - & - & 3.6 & 5.5 & - & 0.3 & 0.02 & 0.01 & 0.03 & Bal. \\
\hline NR6 & 13.9 & 15.3 & 2.2 & 3.7 & - & 2.9 & 4.6 & - & 0.3 & 0.02 & 0.01 & 0.03 & Bal. \\
\hline N19 & 13.2 & 12.2 & 4.6 & 3.0 & 1.5 & 2.9 & 3.6 & - & 0.25 & 0.015 & 0.01 & 0.05 & Bal. \\
\hline FGH98 & 12.65 & 20.2 & 3.83 & 2.18 & 0.9 & 3.45 & 3.7 & 2.31 & - & 0.054 & 0.021 & 0.05 & Bal. \\
\hline
\end{tabular}

During the duty cycle (take off - cruise - landing) of the aeroengines, turbine discs are subjected to cyclic mechanical stresses, thermal stresses and vibration stresses, which usually leads to low cycle fatigue failure in turbine discs. In order to avoid service failures of turbine discs, the focus has been on understanding fatigue damage along with the interaction of creep and environmental damage in turbine disc alloys [4, 8-12]. Extensive studies have been conducted to investigate the fatigue performance of PM superalloys, in order to develop more fatigue-resistant disc alloys and to promote the application of new PM superalloys in turbine discs so as to optimize disc design. Usually low cycle fatigue tests are employed to evaluate the fatigue performance of disc alloys to obtain S-N curves which can be useful for the total life design of turbine disc and materials ranking approaches [13-16]. In addition, FCG tests are used to assess the crack growth resistance of disc alloys and to obtain FCG rate 
information (i.e. da/dN vs. $\Delta \mathrm{K}$ ) curves at various temperatures and loading conditions [10-12, 17-19]. These da/dN vs. $\Delta \mathrm{K}$ curves of PM Ni-based superalloys are essential in enabling the damage tolerance design of turbine discs.

As damage tolerance design prevails in these more advanced aeroengines, the FCG behaviours and the associated mechanisms of PM Ni-based superalloys have received more and more attention. Moreover, FCG behaviours under dwell fatigue conditions in aggressive environments have become of increasing concern due to the increased turbine inlet temperatures which will cause more significant creep and environmental damage superimposed onto the fatigue damage processes and can accelerate the crack growth by one or two orders of magnitude $[11,12,17,19,20]$. Understanding the FCG behaviours and mechanisms operational in these service regimes for the new PM alloys is crucial for the development of more advanced disc alloys and their continued application in turbine discs.

Fatigue performance of Ni-based superalloys has been reviewed in several recent publications $[4,9,21-23]$, with special emphasis on deformation modes and fatigue life in Ni-based superalloys or FCG in cast \& wrought Ni-based superalloys, e.g. Prakash et al. [21] reviewed long FCG micro-mechanisms in IN718 under the combined influence of fatigue, creep and oxidation. However, the FCG behaviours and the over-arching related mechanisms in $P M$ Ni-based superalloys have not been extensively reviewed in these papers. Therefore, this review will focus in particular on the FCG mechanisms in PM Ni-based superalloys (including both short and long FCG behaviours). The effects of microstructural features of advanced PM Ni-based superalloys and their interaction with the effects of external service conditions such as temperature, environment and complex loadings are carefully and extensively reviewed, with a particular focus on the relevant literature in this area in the past two decades.

\section{Short fatigue crack growth mechanisms}

\subsection{Characteristics of short fatigue crack growth and research methodologies}

Generally, fatigue crack initiation occurs in relation to strain localization that is usually associated with a microstructural heterogeneity which gives rise to a local stress concentration. 
In this review, crack initiation is defined as the nucleation of a microstructural crack and differs from the definition of "crack initiation" used in typical engineering terminology (which usually includes crack nucleation and a certain amount of crack growth before the crack length is detectable by in-service engineering or inspection processes). In PM Ni-based superalloys, fatigue cracks mainly initiate at metallurgical defects (e.g. non-metallic inclusions and pores)[13, 24-26], twin boundaries [27, 28], slip bands [27-30] and precipitates $[31,32]$ in the absence of environmental effects. At elevated temperatures, environmental damage enhanced intergranular crack initiation is also commonly observed in aggressive environments [10, 33-37].

Immediately after initiation, the FCG process strongly interacts with local microstructural features ahead of the crack tip and is also influenced by temperature, environment and loading conditions $[4,8,24,38-42]$. These cracks in their early propagation stages are usually named short or small cracks, and their plastic zone ahead of the crack tip is usually comparable to the crack length and thereby linear elastic fracture mechanics (LEFM) are not applicable in describing the crack driving force/crack tip stress state. It is widely accepted that the most distinctive characteristics of short fatigue cracks are their abnormally high but greatly scattered growth rate below the stress intensity threshold of long crack observations and a strong interaction with local microstructural features as shown in Fig. 2 $[38,39]$.

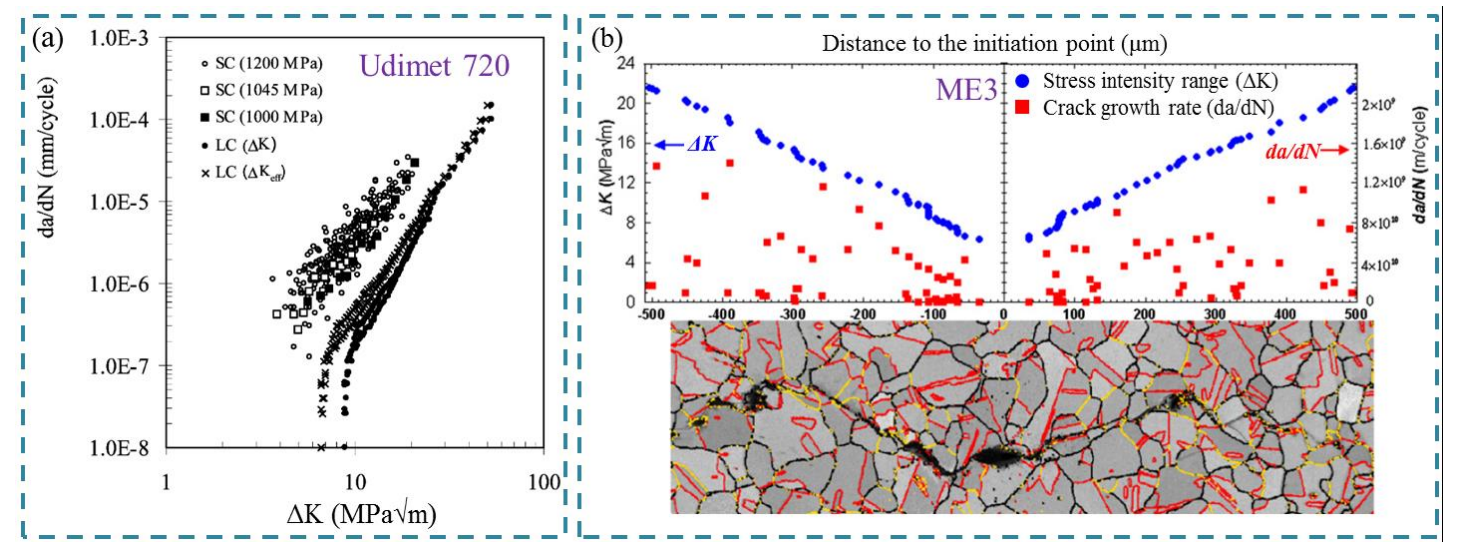

Fig. 2 (a) Short FCG behaviours vs. long FCG behaviours in PM Ni-based superalloy Udimet 720 and (b) the interaction of short fatigue crack with local microstructures in PM Ni-based superalloy ME3 [38, 39]. 
Generally, these short FCG processes contribute to the majority of the fatigue life of PM Ni-based superalloys during service due to the high overall component stresses which result in a relatively small extent of FCG prior to fast fracture [24, 29, 38, 43-45]. Although the short FCG regime accounts for a large proportion of the fatigue lifetime in typical applications of PM superalloys, studies on short FCG in PM superalloys are not abundant and the majority of reported studies were conducted at room temperature which is not relevant to the expected service conditions. This is due to the difficulty in capturing the short FCG behaviour immediately after crack initiation and also the time consuming nature of short FCG tests (especially at high temperature). As the crack itself and crack tip interaction region generally spans only several grain diameters, short cracks cannot be detected by conventional methods of non-destructive materials testing such as ultrasonic testing, which typically provide a resolution of the order of $0.5 \mathrm{~mm}$. Currently the most widespread method to investigate short FCG behaviour is limited to surface observations via replicating the morphology of cracks with acetate or silicone compounds, and examining the resultant replica via optical and scanning electron microscopy (SEM) [24, 30, 44]. This technique is quite time consuming as it requires periodic interruption of the test, cooling and then replication of the surface (potentially influencing subsequent crack growth behaviour). Direct current potential drop (DCPD) has also been applied in characterization of short crack growth, but the DCPD method was found to be inappropriate for very small crack lengths and correct placement of the probes requires prior knowledge of the crack path. Generally, it is difficult to capture the FCG immediately after initiation accurately and in a timely manner due to the randomness of the appearance of the crack. To overcome the uncertainty of capturing behaviour from natural crack initiation sites, to ensure specific areas for investigation of short FCG behaviour, focused ion beams (FIB) were employed to cut notches (acting as artificial cracks) in specimens $[42,46]$. These kinds of FIB notched specimens can be observed in in-situ SEM fatigue tests and then the early short crack growth can be better captured, but this is usually limited by the specimen geometry possible, load capacity, frequency and temperature. Typical in-situ SEM tests will occur under vacuum at room temperature, use of high temperature heating stages or oxidising environments is very problematic in an SEM. Another feasible technique is to use travelling optical microscopes attached in a fatigue test rig with a vacuum 
chamber, which has achieved some high temperature in-situ short fatigue crack observations, but the resolution is still limited and so not able to capture the very early stage growth of short cracks [47]. In addition the effects of oxidation are eliminated in such an experimental set-up. Although recently developed detection methodologies such as high resolution X-ray computed tomography or synchrotron radiation computed tomography can provide a fine resolution (down in some circumstances to $0.8 \mu \mathrm{m}$ ) to examine short cracks in-situ non-destructively in three dimensions (3D), these approaches are challenging to utilize in PM Ni-based superalloys due to X-ray attenuation effects and are also complex to perform at elevated temperatures in representative service environments [17, 48-50].

Despite these challenges in conducting short FCG tests, efforts have still been made to investigate short FCG behaviours and the related mechanisms in PM Ni-based superalloys. These have focussed on the effects of microstructure along with other extrinsic influential factors such as environmental damage. The effects of microstructural features and extrinsic service condition effects on short FCG mechanisms in PM Ni-based superalloys are detailed in the following sections.

\subsection{Effects of microstructure}

\subsubsection{Effects of grain size}

In the absence of environmental effects, short cracks mainly propagate along slip bands after initiation $[8,30,42,51,52]$. It is well accepted that grain size has a significant influence on dislocation motion under either static or cyclic deformation conditions, and thereby impacts the strength of materials. On the one hand, as the grain size increases, the free slip length for dislocations increases accordingly, and the amount of dislocations piling up or pairing along the slip band increases until either the grain boundary becomes ineffective as a barrier for the succeeding dislocations or dislocation sources in the adjacent grains are activated. Therefore, a coarse grain size is apt to promote planar slip, which makes Stage I (as known as mode II) short cracks grow more easily. In addition, the greater the grain size, the lower the number of grain boundaries acting as obstacles to slip transmission of dislocations, resulting in poor crack growth resistance. On the other hand, the enhanced planar slip in a coarse grained structure is also associated with increased slip reversibility giving lower 
intrinsic damage accumulation and also more tortuous crack paths (increased shielding) [24, $29,44]$.

Typical influences of grain size on short FCG behaviour at room temperature and $650{ }^{\circ} \mathrm{C}$ can be found in Pang's research on the disc alloy Udimet 720Li [24, 29]. In his work, fatigue crack initiation and short FCG behaviour in Udimet 720Li and its microstructural variants, i.e. Udimet 720Li-LG (large grain variant) and Udimet 720Li-LP (large intragranular coherent $\gamma^{\prime}$ precipitate variant) have been assessed by replicated short FCG tests. It is found that short FCG exhibits a highly faceted fracture surface due to planar slip band cracking occurring immediately after crack initiation followed by a transition to a flatter Stage II type crack path as crack length increases at room temperature. Udimet $720 \mathrm{Li}-\mathrm{LG}$ shows a slightly improved FCG resistance compared with as-received Udimet $720 \mathrm{Li}$ because of the increased slip reversibility, although its fatigue lifetime is less than that of Udimet $720 \mathrm{Li}-\mathrm{LP}$ due to the relatively lower fatigue crack initiation resistance. At elevated temperature $\left(650^{\circ} \mathrm{C}\right)$, a transition from transgranular FCG to oxidation-assisted intergranular FCG can be observed after the short crack propagates beyond four to six grains in air. Udimet 720Li-LG shows the most significant performance benefits in terms of overall fatigue lifetime under the test conditions as the larger grain size not only prolongs the initial slow transgranular FCG after crack initiation but also improves high temperature oxidation-assisted intergranular FCG resistance due to less embrittled grain boundaries.

However, it is noteworthy that it is difficult to control only one microstructural variable during processing of PM Ni-based superalloys. Grain size variation is usually accompanied by a change in $\gamma^{\prime}$ size, which also influences the short FCG behaviour. Jiang [30] studied the short FCG behaviours in coarse grained (CG) and fine grained (FG) LSHR alloys processed by supersolvus and subsolvus heat treatment (HT) respectively. It is found that although the fatigue lifetime is higher in the FG LSHR variant than that of CG LSHR variant, the short FCG rates are similar in these two LSHR variants at room temperature. Detailed analysis with electron backscatter diffraction (EBSD) indicates that cracks preferentially propagate along slip bands associated with high Schmid factor (SF) slip systems after initiation. Small grains with low SF are more resistant to short FCG compared to large grains with high SF. Full field 
strain measurement was carried out (using SEM-DIC) with sub-micron resolution ahead of the crack tip in the LSHR alloy where artificial cracks were prepared by FIB. This showed that FCG occurred along, and very close to, twin boundaries indicating that crack advance is determined by the cracking of slip bands at the crack tip accompanied by the appearance of transverse strain in the slip bands [42].

\subsubsection{Effects of grain orientation}

It is worth mentioning however that short FCG is a complicated function of various microstructural factors. Apart from the grain size, the crystallographic orientation of the grains (or GB misorientation) and their respective slip planes impact the dislocation slip transmission and therefore the short FCG behaviour to a significant extent. It is believed that the retardation effects of grain boundaries on transgranular short FCG are determined by the crystallographic orientation of neighbouring grains, i.e. the low angle grain boundaries are less effective in hindering the short FCG, whereas boundaries with higher misorientation angles on average tend to cause larger crack deflections/crack arrest and result in larger FCG retardations (if the segregation, precipitation and oxidation of grain boundary are not taken into account) [52, 53]. Based on Miao's study [52], fatigue cracks were seen to subsequently grow in grain clusters within which grains are misoriented by less than $20^{\circ}$ relative to the initiation grains, as observed in Rene 88DT. More highly misoriented neighbouring grains resulted in crack arrest [52]. Additionally, at fixed grain-boundary misorientation angles, special boundaries are no more effective than random boundaries in impeding transgranular short FCG, as observed in PM superalloy ME3 processed by grain boundary engineering [38, 54].

Furthermore, the spatial arrangement of slip planes in the adjacent grains or misorientation of neighbouring slip planes is a more critical influential factor on short FCG than the misorientation of neighbouring grains, according to Zhai's research [55]. This is schematically shown in Fig. 3 and supported by a direct 3D observation of the interaction between short cracks and grain boundaries in the recently employed application of FIB tomography [56-58]. It is shown that the grain boundary can still continue to exert an 
effective drag on the crack front due to fracture of the area "abc" on the grain boundary plane (Fig. 3) after the crack tip passes the grain boundary on the surface, until the crack crosses the whole grain boundary plane beneath the surface because of the normally semi-elliptical shape of a short fatigue crack. Therefore the twist angle $\alpha$ (as defined in Fig. 3) of two slip planes/crack planes has a more significant influence on short FCG compared to the tilt angle $\beta$ (as defined in Fig. 3) of the crack paths in the two adjacent grains at the surface. As a result, the growth rate of the crack tip inside a given grain on the specimen surface is still significantly influenced by the grain boundary that it has just passed on the surface, in addition to the orientation of that grain.

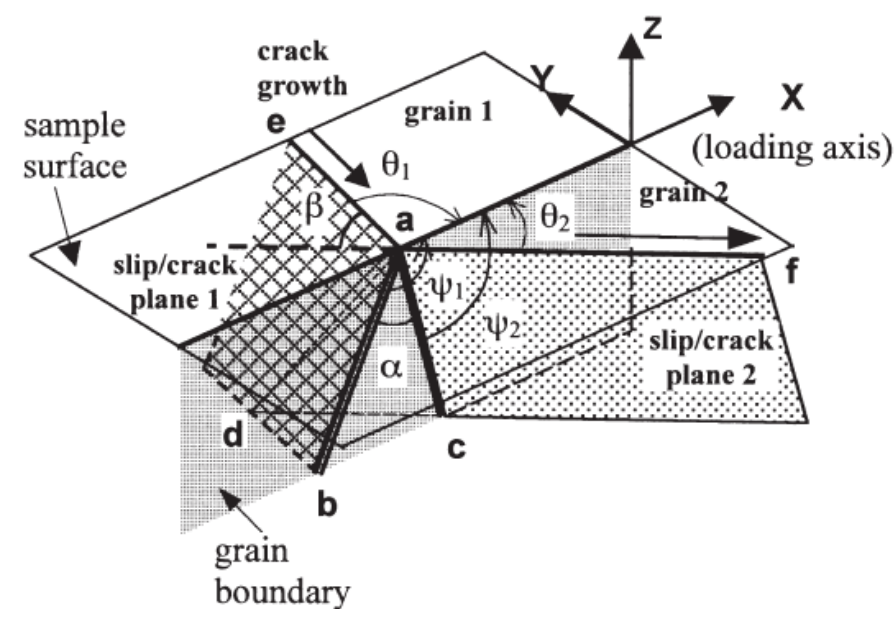

Fig. 3 Schematic diagram showing a crystallographic mechanism for crack growth along slip plane 1 in grain 1 into slip plane 2 in grain 2 [55].

At elevated temperatures, the short fatigue crack propagates in a more intergranular mode. The influence of grain orientation on intergranular short FCG at elevated temperatures is manifested by stress/strain assisted degradation (e.g. oxidation and corrosion) of grain boundary properties which is related to strain accumulation and stress concentration in the vicinity of grain boundaries. The orientation-dependent strain accumulation or stress concentration at grain or subgrain level can be measured by high resolution digital image correlation (DIC) in combination with EBSD $[25,42,59,60]$, and can be simulated by crystal plasticity finite element modelling [61, 62]. Generally, large misorientations between neighbouring grains or large differences in Schmid factor of the active primary slip systems in 
the neighbouring grains are associated with significant dislocation pile-ups and strain accumulation $[59,63]$, and thereby may facilitate the degradation processes of grain boundary properties induced by oxidation and/or corrosion. In addition, the grain boundary energy which is associated with grain orientation and the lattice coherence of the neighbouring grains also has influence on the grain boundary degradation processes and further influences the intergranular short FCG $[54,64,65]$. Based on the coincident site lattice (CSL) model, low angle grain boundaries and special grain boundaries with low CSL $\Sigma$ value usually correspond to low grain boundary energy [66-68], which means these grain boundaries are more insensitive to environmental attack. For instance, the frequent observed crack initiation and early propagation along slip bands parallel and adjacent to $\Sigma 3$ twin boundaries (with a misorientation angle of $60^{\circ}$ ) in Ni-based superalloys at low temperatures are closely related to the strain accumulation around these $\Sigma 3$ twin boundaries [28, 30, 42, 59], whereas $\Sigma 3$ twin boundaries show good resistance to short FCG at elevated temperatures due to the high lattice coherence and low grain boundary energy as well as more homogeneous deformation (seen at elevated temperatures).

\subsubsection{Effects of $\gamma^{\prime}$ precipitates}

$\gamma^{\prime}$ precipitates are the main strengthening phase in PM Ni-based superalloys. Their size and distribution can be tailored by heat treatments, which can consequently modify the mechanical properties of PM Ni-based superalloys. Generally speaking, $\gamma^{\prime}$ precipitates, especially secondary and tertiary $\gamma^{\prime}$ precipitates due to their large volume fraction compared with the primary $\gamma^{\prime}$ precipitates, are effective barriers for dislocation motion, and thereby they are also effective barriers for FCG. Depending on the $\gamma^{\prime}$ precipitate size, dislocation-precipitate shearing or looping mechanisms can occur, producing planar slip or wavy slip, which influences in particular early transgranular FCG. In general, it is usually observed that finer $\gamma^{\prime}$ precipitates are more likely to exhibit precipitate shearing, whereas coarser $\gamma^{\prime}$ precipitates tend to experience both precipitate shearing and looping mechanisms in PM Ni-based superalloys $[1,4,42,44,69]$. The $\gamma^{\prime}$ precipitate shearing mechanism is associated with heterogeneous slip indicating enhanced slip reversibility, which can result in lower FCG rates [44]. On the other hand, comparatively less precipitate shearing takes place 
as precipitate size increases, which is associated with less planar slip but more homogeneous deformation and more accumulated damage under cyclic loading.

Moreover, the retained primary $\gamma^{\prime}$ in PM Ni-based superalloys after solution heat treatment produces an elastic strain field which is expected to interact with cracks, and it may accelerate or decelerate early short FCG or even cause the crack temporarily to arrest at primary $\gamma^{\prime} / \gamma$ interfaces as seen in Udimet $720 \mathrm{Li}[29,43,44]$. With traditional metallurgical sectioning methods, it is found that the cracks can either cut through the primary $\gamma^{\prime}$ precipitates or deflect at the interfaces of primary $\gamma^{\prime}$ precipitates and matrix materials depending on the degree of coherence and the elastic-plastic properties of the respective particles with respect to the surrounding matrix material. In some cases, the cracks are arrested by the precipitates and then stop growing for a few thousands of cycles before the FCG resumes or even stop growing completely [29]. Recently, the interaction between short cracks and precipitates has been carefully investigated by 3D FIB tomography techniques in a Ni-based superalloy [70]. It is reported that the crack tends to bypass the precipitates by forming steps in the crack plane and this behaviour depends on the mechanical properties of the precipitates with respect to the matrix material. However, as mentioned previously, it is difficult to control individual microstructural variables independently during processing of PM Ni-based superalloys, the effects of primary $\gamma^{\prime}$ precipitates on short FCG are usually coupled with change in other microstructural variables (e.g. different volume fraction, size and distribution of primary, secondary and tertiary $\gamma^{\prime}$ precipitates are usually interlinked). Further study of the effects of $\gamma^{\prime}$ precipitates on short FCG behaviour requires control of the $\gamma^{\prime}$ precipitation behaviours to evaluate the individual effects of primary, secondary and tertiary $\gamma^{\prime}$ precipitates on short FCG.

At elevated temperatures, the effects of $\gamma^{\prime}$ precipitates may become less significant due to co-occurring environmental damage. In the cases where oxidation exists, the precipitates/matrix interfaces are usually the preferential path for early FCG due to the degradation of these boundary properties [10-12]. In the cases where environmental damage is absent, the influence of $\gamma^{\prime}$ precipitates on short FCG at elevated temperatures is generally embodied by the influence of temperature on the dislocation slip behaviours with respect to $\gamma^{\prime}$ precipitates in Ni-based superalloys. At high temperatures, the additional thermal energy 
stimulates the activation of secondary slip and cross-slip of dislocations [71], resulting in reduction of critical resolved shear stress and causing short cracks to grow less crystallographically. In addition, when long dwell load is employed, these effects are associated with possible stress relaxation/creep behaviour at the crack tip. However, there are few studies of the effects of $\gamma^{\prime}$ precipitate distribution on short FCG in PM Ni-based superalloys at elevated temperatures, which is probably due to the difficulties both in controlling the size and distribution of $\gamma^{\prime}$ precipitates and observing the short FCG behaviour at elevated temperatures at high spatial resolution.

\subsubsection{Effects of non-metallic inclusions}

Non-metallic inclusions inherent from powder atomisation processes are important and unavoidable metallurgical defects in PM Ni-based superalloys [13, 25]. As the short fatigue crack growth usually strongly interacts with the local microstructures, the non-metallic inclusions are expected to have evident influences on short fatigue crack growth due to the resultant stress concentration effect if they stay in the fatigue crack growth paths. However, studies of the effects of the non-metallic inclusions on short fatigue crack growth behaviours are quite limited due to the rare occurrence of non-metallic inclusions in PM Ni-based superalloys and the low possibility of capturing the inclusions at the fatigue crack growth paths. The studies with regards to the effects of non-metallic inclusions on short fatigue crack growth in PM Ni-based superalloys that can be found in the open literature were conducted by Xie and Dong [72]. They conducted in-situ fatigue tests on alumina $\left(\mathrm{Al}_{2} \mathrm{O}_{3}\right)$ seeded PM superalloy Rene'95, and found the crack may propagate directly into or through the inclusion and the inclusion can be cut or broken into two or more pieces. TEM observation revealed the dislocations pile up at the inclusion/matrix interface to form stress concentration, and the mismatch of deformation between inclusion and matrix leads to crack initiation and propagation at interface before the alloy matrix yields. In addition, Artamonov [73] recently investigated the fatigue crack growth mechanism in PM Ni-based superalloy EP741NP, and found that a rugged rough surface of the crack consisted of spherical particles with the size in the range between 50 and $150 \mu \mathrm{m}$ was form at the beginning in the case of subsurface crack initiation from inclusions. In this subsurface short fatigue crack growth from inclusions, nano-grains with the size of $100-200 \mathrm{~nm}$ were formed in front the crack tip and these 
misoriented nano-grains led to the appearance of relatively "weak" links at nano-grain boundaries, which resulted fatigue crack grew through the boundaries of nano-grains [73]. When a crack reached to specimen surface and then air accessed into the crack space, the crack surface changed to a quasi-facet morphology. Although these studies provide some insights into the effects of non-metallic inclusions on short fatigue crack growth in PM Ni-based superalloys, further studies are apparently needed to disclose the role of non-metallic inclusions in strain localisation and cracking processes during short fatigue crack growth.

\subsection{Extrinsic effects on short fatigue crack growth}

Apart from microstructural effects, extrinsic effects including temperature, environment and loading conditions (i.e. loading frequency, load ratio, loading waveform and dwell time) can also exert significant influence on short FCG behaviours. In most cases, these extrinsic (service) effects exert combined influences on short FCG, e.g. high temperature, aggressive environment and low loading frequency can cause enhanced intergranular FCG due to the resultant environmental damage. Several researchers have investigated the short FCG behaviours at elevated temperatures $\left(450^{\circ} \mathrm{C}\right.$ and $\left.650^{\circ} \mathrm{C}\right)$ in RR1000 [44], IN100 [74], Udimet $720 \mathrm{Li}[24,44]$, N18 [75, 76] and LSHR [36]. Generally, enhanced short FCG and increased crack coalescences have been observed at elevated temperatures due to the effects of stress assisted grain boundary oxidation (SAGBO) $[36,40,41,77]$ or dynamic embrittlement of grain boundaries [78-80]. SAGBO is usually more dominant in fine grained PM Ni-based superalloys due to the increased availability of grain boundaries for short circuit diffusion of oxygen. For this reason, Reed et al. [24, 44] claimed that large grain microstructures gave the most significant performance benefits in Udimet $720 \mathrm{Li}$ during short $\mathrm{FCG}$ tests at $650^{\circ} \mathrm{C}$. Due to interaction between fatigue and environment damage during short FCG, the FCG rate is higher at elevated temperatures and individual (single) crack propagation is rarely observed at elevated temperatures in air, especially under dwell-fatigue conditions. As shown in Fig. 4, which shows the FCG rate observed in IN100 [74], initial short FCG rates were observed to be over an order of magnitude faster when tested with a $6 \mathrm{~s}$ dwell period, resulting in a fully intergranular fracture surface, although this 6s dwell period showed a negligible effect on long FCG rates at $650^{\circ} \mathrm{C}$. The significant degree of crack coalescence can be observed in 
LSHR alloy tested at high temperature $\left(725^{\circ} \mathrm{C}\right)$ as shown in Fig. 5. Due to the grain boundary oxidation which produces many small grain boundary cracks, the FCG is predominantly determined by the coalescence of these small grain boundary cracks [40, 81]. In addition, the oxides that form in the crack wake and at the crack tip, along with the plastic deformation left by the wake of propagating crack, a mutual displacement of the two crack faces or the asperities of the fracture surface (which are associated with load ratio) may cause crack closure and then may influence the short FCG behaviour [82-84]. However the crack closure effect on short FCG in PM Ni-based superalloys is rarely investigated and it is believed that crack closure is insignificant in the short FCG regime (due to the high effective load ratios experienced and the lack of significant crack wake).

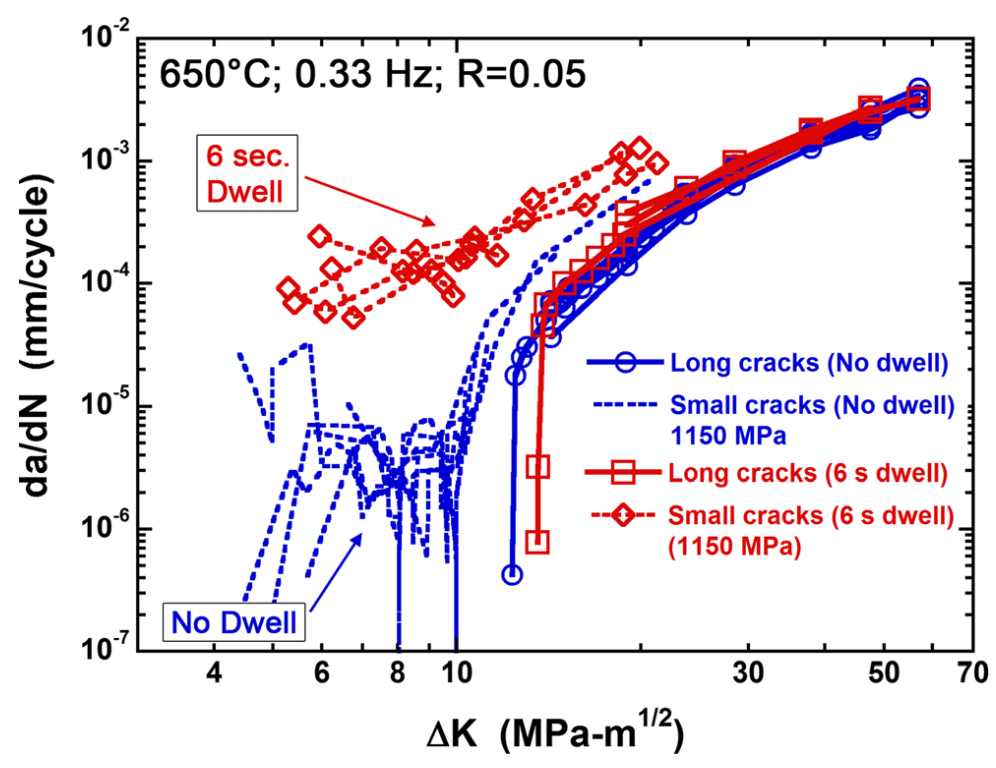

Fig. 4 Effects of dwell time on FCG rates in IN100 [74].

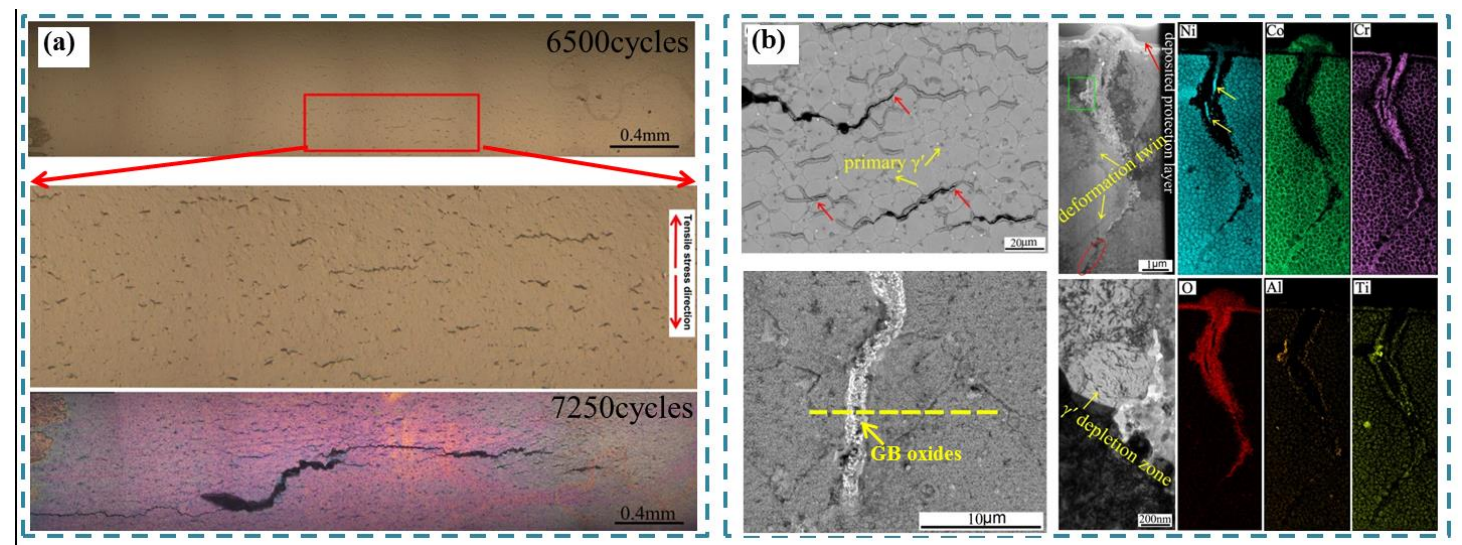

Fig. 5 (a) Short fatigue crack coalescences and (b) grain boundary oxidation in FG LSHR alloy at $725^{\circ} \mathrm{C}[40,81]$. 


\section{Long fatigue crack growth mechanisms}

As a crack propagates, the plastic zone ahead of the crack tip becomes relatively small compared with the crack length itself, which makes LEFM assumptions more applicable to describe FCG behaviour, then such cracks can be termed long cracks. The growth behaviour of a long fatigue crack is the synergistic result of microstructure, temperature, environment in combination with loading conditions, although the influences of microstructure become less significant compared with short FCG [10-12, 17, 19, 39, 85-89]. The resultant fracture mode can be transgranular or intergranular or a mixture of both depending on the specific in-service or testing conditions. Correspondingly, the fatigue behaviour can be termed as cycle-dependent fatigue or time-dependent fatigue on the basis of the degree of crack growth responding to the time-related effects $[85,86]$. Generally, low temperature, high loading frequency in combination with vacuum or inert environment tends to produce cycle-dependent FCG and result in transgranular fracture surfaces with fatigue striations; whereas a high temperature, low loading frequency as well as aggressive environment promotes time-dependent FCG and causes intergranular fracture surfaces [10-12, 17, 19-21, $85,86]$. In the following sections, the mechanisms describing the effects of microstructure on long FCG and the effects of the interaction between fatigue, creep and environmental damage on long FCG are discussed. In some ways, comparing the mechanistic differences observed under long FCG conditions allows a clearer evaluation of the effects of microstructure and test environment interactions as the local crack tip stress state is more comparable and controlled than in the short crack case. There is also a much larger literature available reporting on long crack studies in these systems.

\subsection{Effects of microstructure}

\subsubsection{Effects of grain size}

After crack initiation, the crack-propagation direction changes from close to $45^{\circ}$ to $90^{\circ}$ with respect to the remote normal stress after passing through a few grains (i.e. Stage II crack growth is established), and then FCG behaviour is relatively insensitive to grain misorientation. Even though the influences of microstructure on long FCG become less 
significant, improved FCG resistance has still been observed in Ni-based superalloys with a coarse grained microstructure and large coherent precipitates under the same testing conditions, such as in PM Astroloy [90], Udimet 720Li [5, 91, 92] and LSHR [11, 16, 17]. This has been explained as being due to the longer slip paths and enhanced slip reversibility, as well as more significant crack deflection and crack closure effects. This is despite the expected competing effects of fewer grain boundaries which can act as crack-growth barriers and a lower degree of discontinuity, which should make cracks able to propagate more continuously, resulting in poorer FCG resistance [91, 93-97]. A detailed study of effects of grain size on FCG behaviour in an advanced disc alloy LSHR has been conducted in air and vacuum by Jiang et al, the faster FCG rate is observed in the FG LSHR than that in CG LSHR in vacuum (Fig. 6) $[11,17]$. The statistical distribution of grain-size, primary and secondary $\gamma^{\prime}$ size in the investigated LSHR variants are presented in Table 2. Although transgranular fracture morphologies are observed in both FG and CG LSHR alloys, the CG LSHR variant shows crystallographic facets on the fracture surface but no such facets on the FG LSHR fracture surface, indicating more planar slip and more inhomogeneous deformation in the CG LSHR alloy. The slower FCG rate in the CG LSHR further verified that the beneficial effect of increased slip reversal overweighs the detrimental effect of slip continuity in the CG LSHR superalloy, contributing to better FCG resistance. However, it is important to note that other microstructural features (such as $\gamma^{\prime}$ size) may make contributions to the FCG simultaneously along with the effects of grain size, but it is difficult to obtain PM superalloy variants with varying grain sizes while keeping other microstructural features identical.

Table 2 Statistics results of size of grain, primary and secondary $\gamma^{\prime}$ in LSHR variants $[11,17]$.

\begin{tabular}{lccc}
\hline Materials & Grain size $(\mu \mathrm{m})$ & Primary $\gamma^{\prime}(\mu \mathrm{m})$ & Secondary $\gamma^{\prime}(\mathrm{nm})$ \\
\hline CG LSHR & $38.38 \pm 18.07$ & N/A & $153 \pm 29$ \\
FG LSHR & $8.14 \pm 2.77$ & $1.74 \pm 0.48$ & $89 \pm 15$ \\
MG LSHR & $19.85 \pm 7.82$ & N/A & $221 \pm 28$ \\
\hline
\end{tabular}

For tests conducted in air, the faster FCG in the FG LSHR is related to environmental damage such as oxidation along grain boundaries ahead of the crack tip. It is well known that the grain boundary usually acts as a short-circuit diffusion path of the oxidizing species due to 
its relatively high defect density (such as vacancies and dislocations). The FG structure is usually associated with more severe preferential oxidation along grain boundaries due to the larger number of available grain boundaries, and thus accelerates the FCG [11, 12, 90, 97]. In terms of the effects of environmental damage on FCG, further discussion will be presented in Section 3.3.

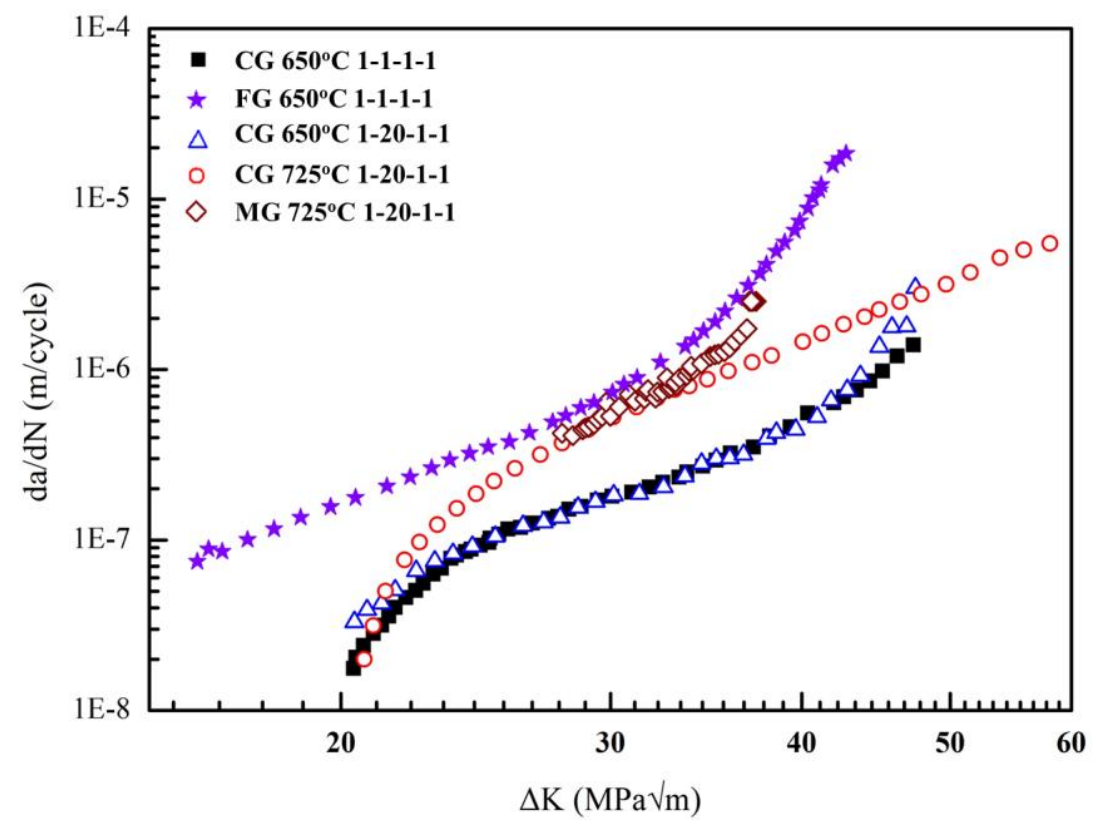

Fig. 6 FCG rate in LSHR alloys with different grain sizes in vacuum $[11,17]$.

\subsubsection{Effects of $\gamma^{\prime}$ precipitates}

Although it is difficult to vary the grain size while keeping other microstructural features identical, it is possible to vary the $\gamma^{\prime}$ size (especially secondary and tertiary $\gamma^{\prime}$ size) while keeping the grain size identical. As shown in Zhang's study [98], fine secondary and tertiary $\gamma^{\prime}$ can provide better cycle-dependent FCG resistance compared to relatively coarse secondary and tertiary $\gamma^{\prime}$ in a PM superalloy FGH96 using a non-dwell loading waveform. They also observed that the shape of secondary $\gamma^{\prime}$ has an influence on the FCG rate and indicated that secondary $\gamma^{\prime}$ in the shape of a "butterfly" shape presents enhanced resistance, compared to that detected in an octagonal shape as shown in Fig. 7. But it seems that the FCG rate was not solely affected by secondary $\gamma^{\prime}$ shape, as the secondary and tertiary $\gamma^{\prime}$ size are different in these two FGH96 microstructural variants. In fact the finer (tertiary) $\gamma^{\prime}$ size is most likely to control slip behaviour. 

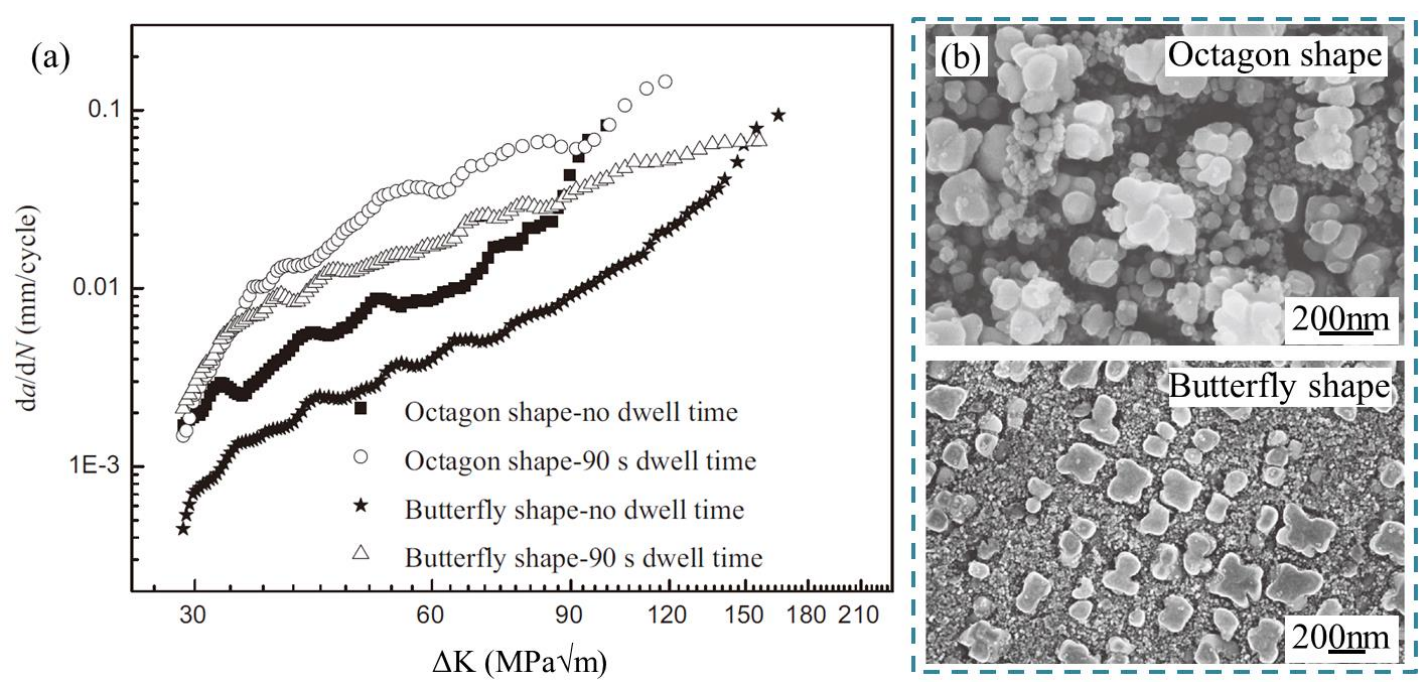

Fig. 7 (a) Effects of secondary $\gamma^{\prime}$ shape on fatigue crack growth rate and (b) morphology of secondary $\gamma^{\prime}$ in PM nickel-based superalloy FGH96 [98].

Maciejewski and Ghonem [88] investigated the influence of precipitates on intergranular FCG of PM nickel-based superalloy IN100. By performing different heat treatments and/or long term exposures, five subsolvus heat treated IN100 microstructural variants were obtained with varying secondary and tertiary $\gamma^{\prime}$ size and volume fraction while the size and volume fraction of matrix grains were kept identical (Table 3). Normally, high cooling rate is associated with fine secondary $\gamma^{\prime}$ precipitates, whereas the tertiary $\gamma^{\prime}$ sizes are synergistically controlled by cooling rate from solution heat treatment, aging heat treatment and subsequent thermal exposures. It is found that the FCG rate is influenced by the size and volume fraction of secondary and tertiary $\gamma^{\prime}$ precipitates at $650^{\circ} \mathrm{C}$, but this $\gamma^{\prime}$-sensitive FCG behaviour is diminished at $700^{\circ} \mathrm{C}$, where was assumed that the grain boundary cracking process is dominated by environmental damage at $700^{\circ} \mathrm{C}$. According to Maciejewski and Ghonem [88], the influence of $\gamma^{\prime}$ precipitates on intergranular FCG is rationalized by their influence on the yield strength of IN100 as shown in Fig. 8. The improved FCG resistance is associated with the high yield strength which is contributed to by the relatively small secondary and tertiary $\gamma^{\prime}$ size. 
Table 3 Yield strength $\left(0.2 \%\right.$ proof stress at $\left.650^{\circ} \mathrm{C}, \sigma_{y}\right)$ and statistics (size, $d$, and volume fraction, $f$ ) of secondary and tertiary $\gamma^{\prime}$ of the as received and heat treated IN100 microstructures.

\begin{tabular}{|c|c|c|c|c|c|}
\hline Specimen (Heat treatment sequence) & $f \gamma^{\prime} t$ & $\begin{array}{l}d \gamma_{t}^{\prime} \\
(\mathrm{nm})\end{array}$ & $f \gamma_{s}^{\prime}$ & $\begin{array}{l}d \gamma_{s}^{\prime} \\
(\mathrm{nm})\end{array}$ & $\begin{array}{l}\sigma_{y} \\
(\mathrm{MPa})\end{array}$ \\
\hline $\begin{array}{l}\text { HT-A: As received }\left(1149^{\circ} \mathrm{C} 2 \mathrm{~h} \text { oil quenched, } 982^{\circ} \mathrm{C} 1 \mathrm{~h} \text { fan }\right. \\
\text { cooled, } 732^{\circ} \mathrm{C} 8 \mathrm{~h} \text { air cooled) }\end{array}$ & 11 & 23 & 29 & 208 & 1042 \\
\hline $\begin{array}{l}\text { HT-B: Overaged }\left(815^{\circ} \mathrm{C} 75 \mathrm{~min} \text { cooled } 1{ }^{\circ} \mathrm{C} / \mathrm{min}, 732^{\circ} \mathrm{C} 30\right. \\
\text { h air cooled) }\end{array}$ & 24 & 23 & 16 & 155 & 1095 \\
\hline HT-C: Long term exposure $\left(650{ }^{\circ} \mathrm{C} 1500 \mathrm{~h}\right.$ air cooled $)$ & 21 & 29 & 19 & 130 & 1119 \\
\hline $\begin{array}{l}\text { HT-D: Very slow cooling from solutioning }\left(1065{ }^{\circ} \mathrm{C} 2 \mathrm{~h}\right. \\
\text { cooled } 1{ }^{\circ} \mathrm{C} / \mathrm{min} \text { for } 10{ }^{\circ} \mathrm{C} \text { with } 10 \mathrm{~min} \text { hold, repeating this } \\
\text { cooling cycle to room temperature, } 982^{\circ} \mathrm{C} 75 \text { min air cooled, } \\
732{ }^{\circ} \mathrm{C} 8 \mathrm{~h} \text { air cooled) }\end{array}$ & 14 & 29 & 26 & 258 & 941 \\
\hline $\begin{array}{l}\text { HT-E: Aging before stabilization }\left(1065{ }^{\circ} \mathrm{C} 2 \mathrm{~h} \text { ice water }\right. \\
\left.\text { quenched, } 732^{\circ} \mathrm{C} 8 \mathrm{~h} \text { air cooled, } 982^{\circ} \mathrm{C} 75 \mathrm{~min} \text { air cooled }\right)\end{array}$ & 25 & 20 & 15 & 209 & 1035 \\
\hline
\end{tabular}
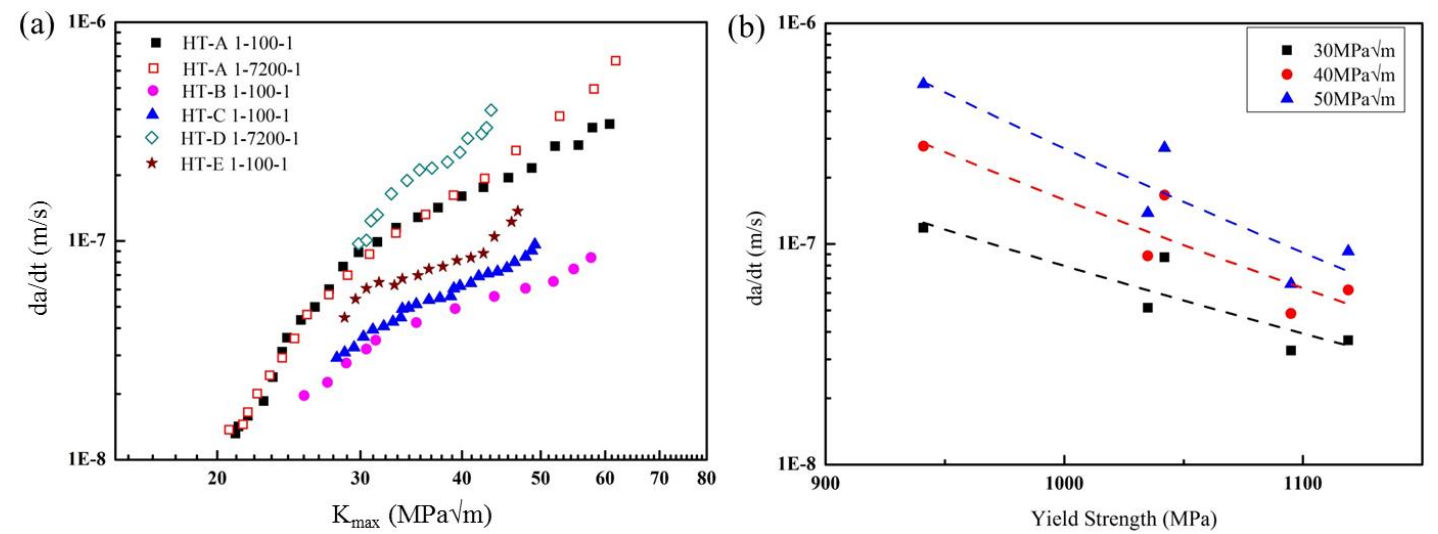

Fig. 8 (a) Effects of secondary and tertiary $\gamma^{\prime}$ precipitates on fatigue crack growth rates and (b) fatigue crack growth rate, at different $\mathrm{K}_{\max }$ values, as a function of experimentally measured yield strength at $650^{\circ} \mathrm{C}$ for the as received and the heat treated IN100 specimens which have the same grain size [88].

By varying the solution heat treatment cooling rate (i.e. $72{ }^{\circ} \mathrm{C}$ and $202{ }^{\circ} \mathrm{C}$ per minute from solutioning temperature) and the subsequent aging steps and thermal exposures, Gabb et al. [99] obtained LSHR variants with similar intrinsic enviromental resistance to crack growth. Further dwell FCG tests on these LSHR variants show that large differences in dwell FCG behaviour still persisted, which were related to their measured stress relaxation behaviours. 
Similar to Ghonem's finding, Gabb et al. [97] found that the dwell FCG tests conducted at $704{ }^{\circ} \mathrm{C}$ resulted in the FCG rates varying by more than two orders of magnitude for the supersolvus heat treated LSHR variants with varying secondary and tertiary $\gamma^{\prime}$ size. It is found that the mean size of tertiary $\gamma^{\prime}$ precipitates is the most important microstructural variable having the largest influence on both dwell FCG and stress relaxation (Fig. 9). On the contrary, the secondary $\gamma^{\prime}$ precipitates were only weakly related to the FCG behavour and the stress relaxation. The larger the mean size of tertiary $\gamma^{\prime}$, the more the significant stress relaxation that occurs at the crack tip, and the stress relaxation is caused by tertiary $\gamma^{\prime}$ coarsening accompanied by the dissolution of fine tertiary $\gamma^{\prime}$ precipitates, although direct observation of mechanisms of stress relaxation, i.e. dislocation gliding or climbing, was absent. This mechanism is further supported by the dwell FCG rate obtained in the CG and FG LSHR variants which have similar secondary $\gamma^{\prime}$ size but varying tertiary $\gamma^{\prime}$ size as shown in Fig. 10 and Table 4. As shown in Fig. 10, accelerated FCG rates are observed in LSHR CGFC1 and FGFC1 with relatively fine tertiary $\gamma^{\prime}$, respectively, although intergranular features were observed in all the LSHR variants. The effect of tertiary $\gamma^{\prime}$ on dwell FCG behavior can be seen more clearly in the LSHR CGFC1 and CGFC2 which have no primary $\gamma^{\prime}$, and the tertiary $\gamma^{\prime}$ is the only variable while keeping the grain size and secondary $\gamma^{\prime}$ size identical [16].

(a)

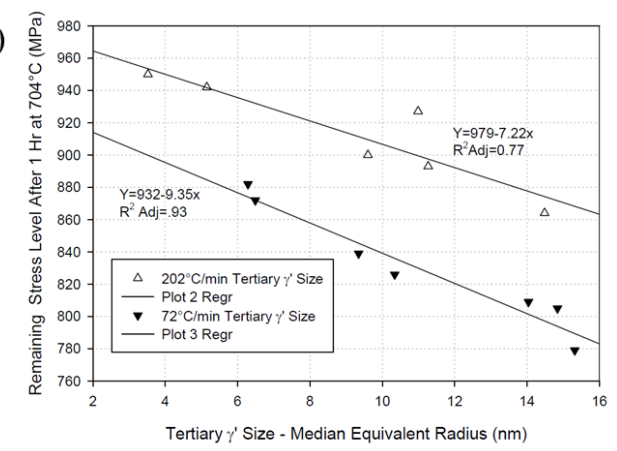

(c)

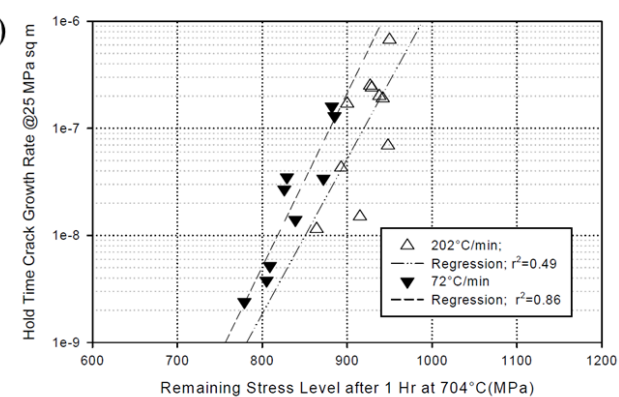

(b)

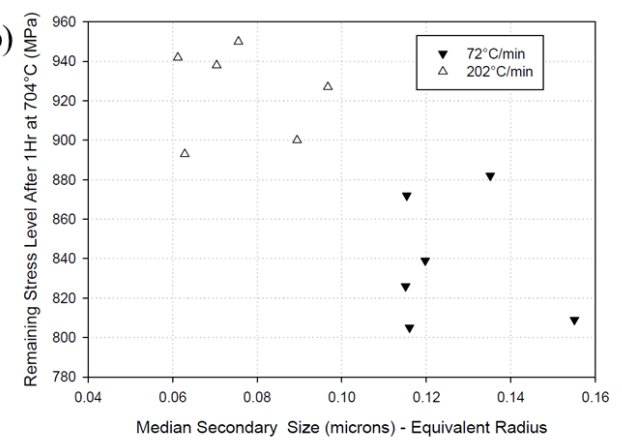

(d)

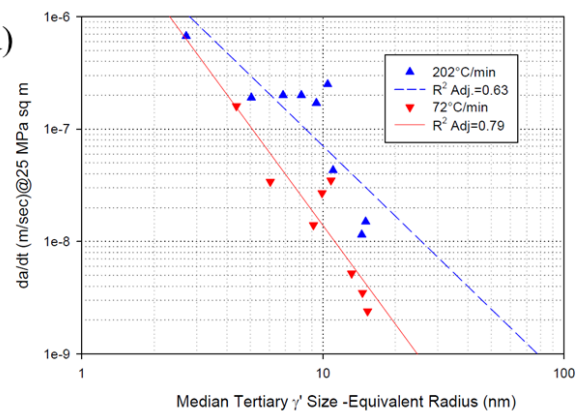

Fig. 9 Relationship between $\gamma^{\prime}$ precipitates size-remaining stress-da/dt: (a) the relationship 
between the tertiary $\gamma^{\prime}$ and stress relaxation; (b) the relationship between the secondary $\gamma^{\prime}$ and stress relaxation; (c) the relationship between the measured dwell fatigue crack growth rates and stress relaxation; and (d) the relationship between tertiary $\gamma^{\prime}$ size and dwell fatigue crack growth rates [97].

Table 4 Typical grain size and $\gamma^{\prime}$ precipitate sizes of the LSHR alloys used in [16]

\begin{tabular}{llll}
\hline Material condition & Grain size $(\mu \mathrm{m})$ & Secondary $\gamma^{\prime}$ radius $(\mathrm{nm})$ & Tertiary $\gamma^{\prime}$ radius $(\mathrm{nm})$ \\
\hline LSHR FGFC1 & 4.3 & $89 \pm 19$ & $11.8 \pm 4.8$ \\
LSHR FGFC2 & 4.2 & $88 \pm 24$ & $16 \pm 3.6$ \\
LSHR CGFC1 & 14.7 & $122 \pm 25$ & $6.5 \pm 3.1$ \\
LSHR CGFC2 & 14.4 & $137 \pm 31$ & $15.1 \pm 3.5$ \\
\hline
\end{tabular}

Note: FG and CG mean that the specimens were solution heat treated at $1135{ }^{\circ} \mathrm{C}$ and $1171{ }^{\circ} \mathrm{C}$ for $1.5 \mathrm{~h}$ respectively. $\mathrm{FC} 1$ and $\mathrm{FC} 2$ mean that the specimens were cooled down by fan air after solution heat treatment followed by $775{ }^{\circ} \mathrm{C} / 8 \mathrm{~h}$ and $855^{\circ} \mathrm{C} / 4 \mathrm{~h}+775{ }^{\circ} \mathrm{C} / 8 \mathrm{~h}$ aging heat treatment, respectively.
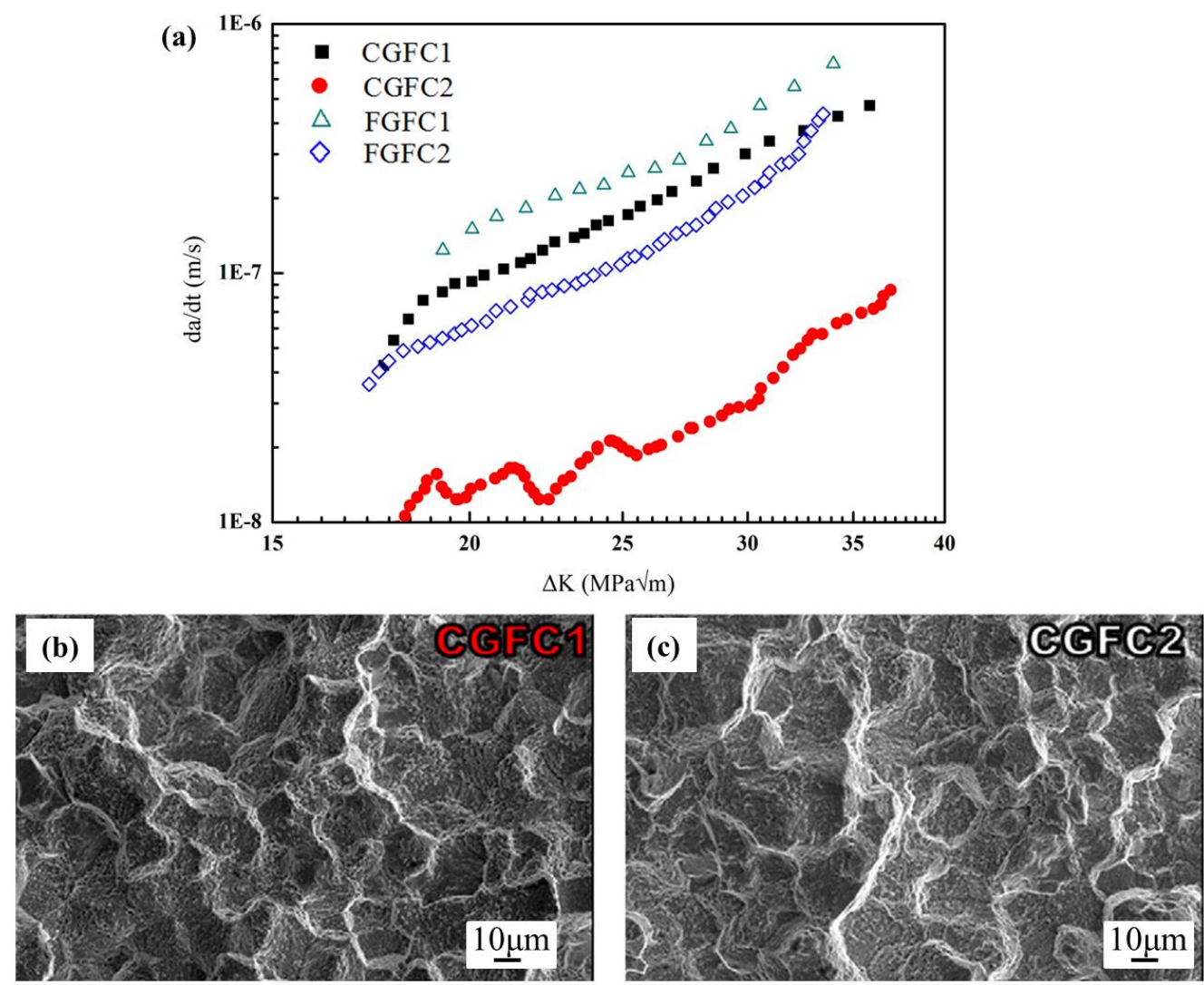

Fig.10 Effects of tertiary $\gamma^{\prime}$ size on fatigue crack growth rate in LSHR alloy: (a) the dwell fatigue crack growth in LSHR variants, the dwell time at the peak stress is 90s; (b) and (c) fractography of CGFC1 and CGFC2 respectively [16]. 
The influence of tertiary $\gamma^{\prime}$ on FCG is also observed in RR1000 [12, 18, 87, 100]. By overaging supersolvus heat treated RR1000 at 700 and $750{ }^{\circ} \mathrm{C}$ from 50 to 500 hours, Bowen et al. [87] investigated coarsening behavior of strengthening $\gamma^{\prime}$ precipitates in coarse grained RR1000, and then conducted dwell FCG tests on these overaged RR1000 variants at $700{ }^{\circ} \mathrm{C}$ in air. The size of secondary and tertiary $\gamma^{\prime}$ in the as-received and overaged RR1000 is presented in Table 5. Compared with baseline ( $0.25 \mathrm{~Hz}$ trapezoidal waveform) FCG tests, a dwell period of 1 hour at the peak load can increase FCG rates by nearly two orders of magnitude as shown in Fig.11. No influence of overaging on baseline FCG behaviour is observed, however, after overaging at $750^{\circ} \mathrm{C}$ for 500 hours (which increases the mean tertiary $\gamma^{\prime}$ size by a factor of two from 17 to $37 \mathrm{~nm}$ ), dwell FCG rates at $700{ }^{\circ} \mathrm{C}$ are reduced by one order of magnitude, indicating the beneficial effects of coarse tertiary $\gamma^{\prime}$ on dwell FCG resistance in PM Ni-based superalloys.

Table 5 RR1000 $\gamma^{\prime}$ precipitate mean diameter with respective standard deviation for all thermal treatment conditions [87].

\begin{tabular}{cccccc}
\hline & Exposure & \multicolumn{4}{c}{ Exposure time $(\mathrm{h})$} \\
\cline { 3 - 6 } & Temperature $\left({ }^{\circ} \mathrm{C}\right)$ & As-received & 50 & 100 & 500 \\
\hline Secondary $\gamma^{\prime}$ & 700 & $174 \pm 46$ & $177 \pm 48$ & $182 \pm 47$ & $199 \pm 57$ \\
$(\mathrm{~nm})$ & 750 & $176 \pm 50$ & $205 \pm 64$ & $189 \pm 56$ & $203 \pm 59$ \\
Tertiary $\gamma^{\prime}(\mathrm{nm})$ & 700 & $16 \pm 3.9$ & $18 \pm 4.5$ & $20 \pm 4.9$ & $25 \pm 5.9$ \\
& 750 & $17 \pm 4.0$ & $28 \pm 6.6$ & $31 \pm 7.2$ & $37 \pm 7.7$ \\
\hline
\end{tabular}

Note: The average grain size of the isothermal treatment samples is $34 \mu \mathrm{m}$ with a standard deviation of $25 \mu \mathrm{m}$.
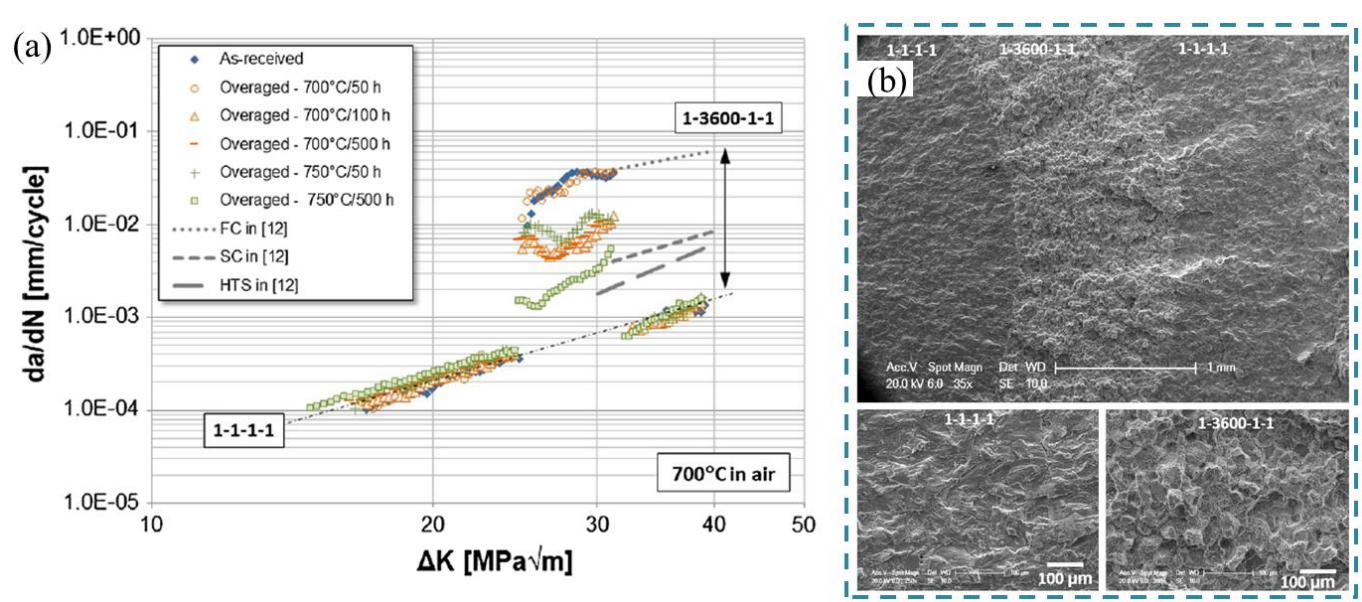

Fig. 11 (a) Effects of tertiary $\gamma^{\prime}$ size on fatigue crack growth rate in RR1000 and (b) morphology of fracture surface [87]. 
In addition to secondary and tertiary $\gamma^{\prime}$ precipitates, primary $\gamma^{\prime}$ precipitates which are inherent from subsolvus solution heat treatment may also exert influences on FCG behaviours as they may be able to block or deflect the cracks as observed in the sobsolvus heat treated LSHR superalloy [11]. However, detailed study on the effect of primary $\gamma^{\prime}$ on FCG behaviours is rare and may now be necessary, as this is pertinent to the FCG behaviour in the grain size transition zone in these dual microstructure heat treated turbine discs (which possess coarse grains at the disc rim and fine grains at the disc bore to optimise the fatigue and creep resistance of turbine discs) [101].

\subsubsection{Effects of grain boundary character and precipitates}

Apart from $\gamma$ grain and $\gamma^{\prime}$ precipitates, grain boundary precipitates are found to influence FCG behaviour to some extent. As shown in Hunt's study on FCG in RR1000 in air and vacuum at $725^{\circ} \mathrm{C}[100]$, it is suggested that grain boundary sigma-phase precipitation causes an increase in FCG rate in vacuum through increased crack tip cavity nucleation and promotes FCG in air through enhanced oxidation due to chromium depletion and subsequent decreased passivation. In addition, the influences of prior particle boundaries (PPBs), PPB affected zone (PAZ), grain boundary and phase boundary on crack propagation behaviour has been assessed in hot isotropic pressed (HIPed), isothermal forged (Ifed) and heat treated PM superalloy FGH96 variants [102]. In these FGH96 variants, PPBs were prevalent in HIPed specimens, but they transformed to PAZs in IFed specimens by isothermal forging. After the standard heat treatment, PAZs were eliminated, and grain boundaries which were decorated with continuously distributed carbides became prevalent in heat treated specimens. It is found that the grain boundaries in heat treated specimens made the greatest contribution to FCG, and the highest FCG rate was attributed to these predominantly intergranular failures. PPBs also had a pronounced influence on FCG, and the dominant failures of intergranular particles resulted in high FCG rate in the HIPed specimens. However, PAZs made the least contribution to FCG mainly owing to their particular microstructures. Thus, the prevalent failures of PAZs resulted in the lowest FCG rate in the IFed specimens. A schematic diagram depicting the FCG path associated with these microstructural features is shown in Fig. 12. Phase boundaries of large $\gamma^{\prime}$ precipitates in PPBs or PAZs also have accelerating effect on FCG, while their contributions were relatively small. Grain boundary $\mathrm{M}_{23} \mathrm{C}_{6}$ carbides and 
non-metallic inclusions are pertinent microstructural features in PM superalloys, however, they are found to have no critical influence on the long FCG in LSHR and FGH96 superalloys respectively based on the limited studies in the open literature [97, 103]. The trivial influence of non-metallic inclusions on the long FCG is probably because that the plastic zone ahead of the long fatigue crack is well developed and the plastic zone size is far greater than the size of non-metallic inclusions, which makes the stress concentration effects brought by these non-metallic inclusions insignificant. However, grain boundary carbides can exert influences on grain boundary oxidation ahead of the crack tip, which is expected to further influence the long FCG processes. Therefore, effects of grain boundary carbides on the long FCG behaviours in PM Ni-based superalloys need further study.

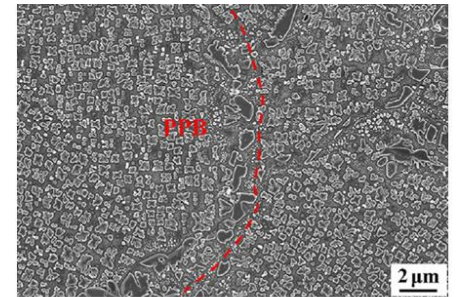

PPB

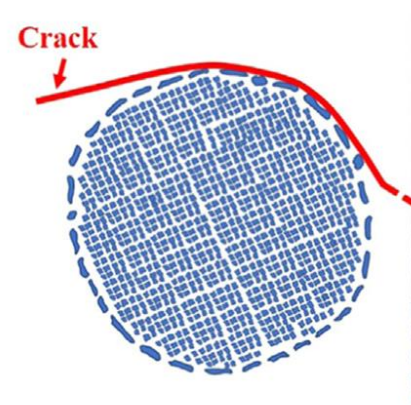

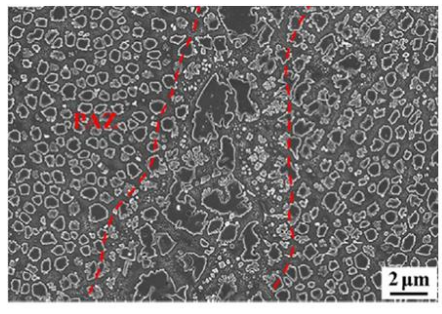

PAZ

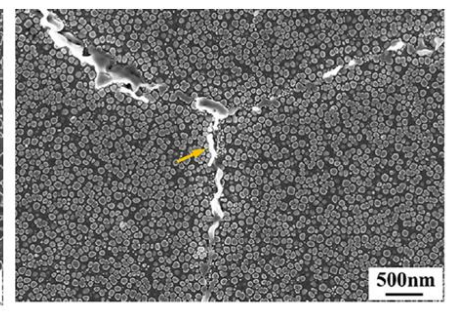

GB

Fig. 12 Effects of grain boundary precipitates on fatigue crack growth behaviours in FGH96 [102].

\subsection{Creep-fatigue crack growth}

In the dwell FCG tests conducted on PM superalloys, the enhanced FCG behaviour associated with the prolonged dwell time at the peak load can be ascribed to the creep and environmental damage during the dwell period $[11,12,20,85,88,89,104-107]$. Similar to the stress relaxation processes at the crack tip, the creep processes at the crack tip are also closely related to the tertiary $\gamma^{\prime}$ coarsening. In fact, the mechanisms responsible for stress relaxation and creep are mainly dislocation climb and grain boundary sliding. Creep refers to the process where the applied stress is kept constant and the material response is that the 
strain is increased, whereas stress relaxation refers to the process where applied strain is kept constant and the material reponse is that the stress reduces. As creep and environmental damage occur simultaneously at the crack tip in air, it is difficult to separate the respective contributions of creep and environmental damage to FCG. Although it might be possible to distinguish creep damage from environmental damage occurring during FCG by fractographic analysis as shown in FGH96 tested in air [105], the differences between the creep features and environmental damage features on the fracture surface are subtle. It is also reported to be possible to distinguish creep and environmental damage contributions by evaluating the related apparent thermal activation energies associated with the FCG behaviour as detailed in [108]. But these methods are still somewhat open to challenge, so to further clarify the effects of creep damage alone on FCG, conducting the FCG test in a vacuum environment is desirable.

Although the dwell FCG is usually termed creep-fatigue crack growth, it appears that creep damage alone makes only a limited contribution to dwell FCG in PM Ni-based superalloys, especially in aggressive environments associated with environmental damage, as shown in Udimet 720Li $[85,104]$. For tests conducted in vacuum, enhanced FCG can be observed in some circumstances due to the creep damage at the crack tip, particularly at longer dwell times $(>20$ s) employed at the peak load, as shown in Fig. 13 (a) in a test comparison of subsolvus heat treated Udimet 720 Li specimens with the same microstructure, showing a transgranular to intergranular transition on the fracture surfaces as the dwell time increases (Figs. 13 (d)-(f)) [104]. This influence of creep damage on enhanced dwell FCG behaviour seems to be diminished at high $\Delta \mathrm{K}$ levels in Udimet $720 \mathrm{Li}$, which is probably related to the high FCG rate at the high $\triangle \mathrm{K}$ levels that results in limited creep damage at the crack tip before the crack tip advances under cyclic loading effects. Conversely, the effects of creep on the FCG behaviour seems to become more significant at high $\Delta \mathrm{K}$ levels in vacuum for subsolvus heat treated RR1000 variants with varying microstructures tested (Table 6) under the same loading condition, also shown in Fig. 13 [100]. These RR1000 variants had different distributions of grain boundary sigma-phase. As the $\Delta \mathrm{K}$ level increases, there is a transition from transgranular to intergranular crack propagation in the as-heat-treated (AHT) RR1000 which has no grain boundary sigma-phase precipitation, indicating the contribution 
of creep damage to crack propagation at higher $\Delta \mathrm{K}$ levels. It was also noted that grain boundary sigma-phase precipitation can promote formation of cavities and enhance intergranular FCG modes, especially at high $\Delta \mathrm{K}$ levels. The dwell FCG in Udimet 720Li and RR1000 indicates that the creep damage at the crack tip and its contribution to FCG is dependent on the local microstructures, FCG rate and $\Delta \mathrm{K}$ level at the crack tip. Although the high stress state at the crack tip with high $\Delta \mathrm{K}$ level can promote the occurrence of creep damage as seen in RR1000, the creep damage may not have time to fully develop if the crack tip advances quickly enough at a high $\Delta \mathrm{K}$ level as seen in Udimet $720 \mathrm{Li}$.

Table 6 Microstructural parameters of RR1000 [100]

\begin{tabular}{cccccc}
\hline Materials & $\begin{array}{c}\text { Wt }(\%) \sigma \\
\text { phase }\end{array}$ & Primary $(\mu \mathrm{m})$ & $\begin{array}{c}\gamma^{\prime} \text { size } \\
\text { Secondary }(\mathrm{nm})\end{array}$ & Tertiary $(\mathrm{nm})$ & $\begin{array}{c}\text { Grain size } \\
(\mu \mathrm{m})\end{array}$ \\
\hline A-H-T & 0.0 & $1 \sim 5$ & 225 & $5 \sim 25$ & $8 \sim 12$ \\
Exp\#1 & 1.0 & $1 \sim 5$ & 228 & $/$ & $8 \sim 12$ \\
Exp\#2 & 0.20 & $1 \sim 5$ & 225 & $/$ & $8 \sim 12$ \\
\hline
\end{tabular}

(a)
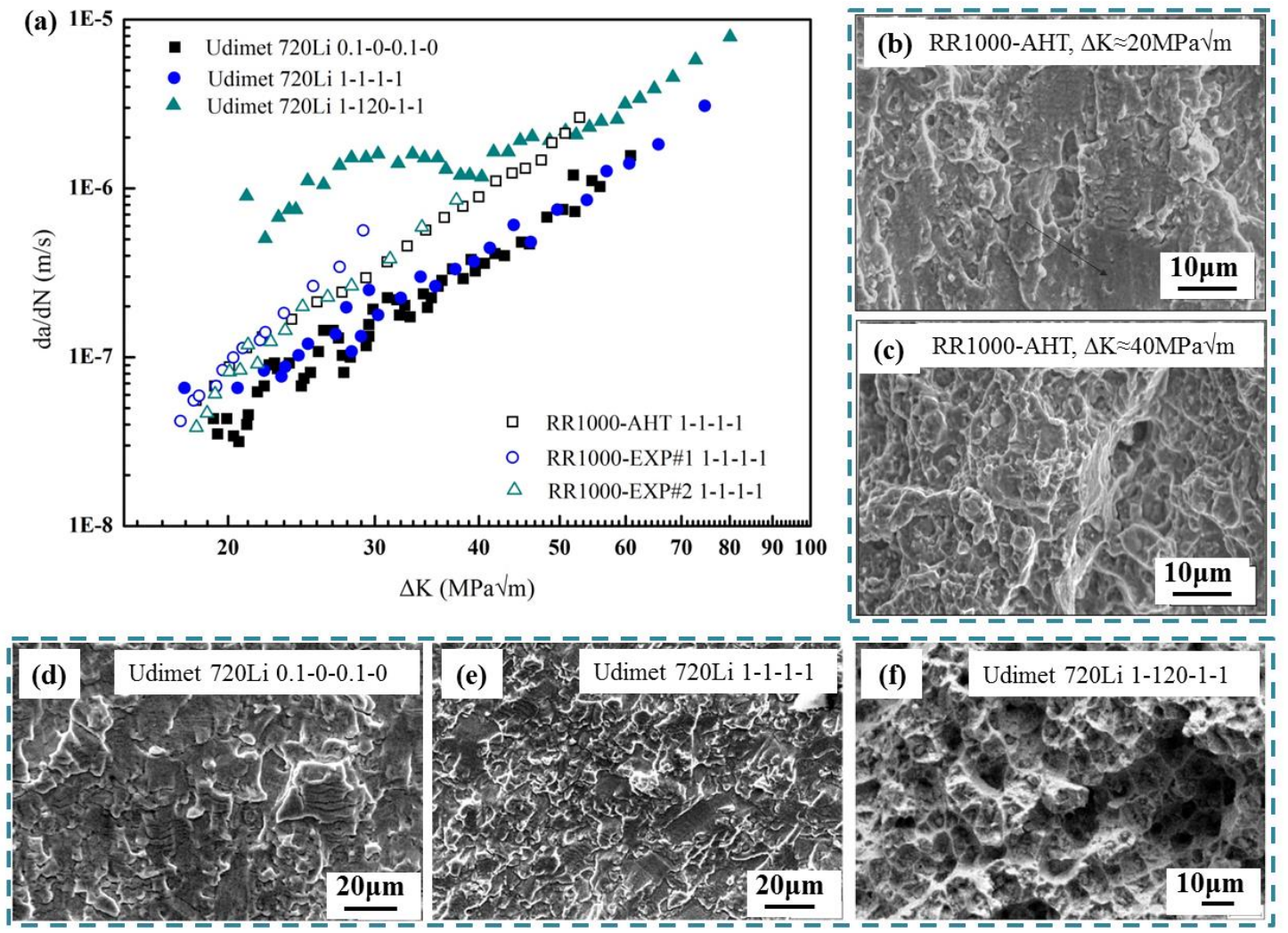

Fig. 13 (a) Effects of creep on FCG in subsolvus heat treated Udimet 720 tested at $700{ }^{\circ} \mathrm{C}$ and in RR1000 variants tested at $725{ }^{\circ} \mathrm{C}$ with a load ratio of 0.5 in vacuum; (b) mixed mode fracture of as-heat-treated $\mathrm{RR} 1000$ at $\Delta \mathrm{K} \approx 20 \mathrm{MPa} \sqrt{ } \mathrm{m}$; (c) intergranular fracture of 
as-heat-treated $\mathrm{RR} 1000$ at $\Delta \mathrm{K} \approx 40 \mathrm{MPa} \sqrt{ } \mathrm{m}$; (d), (e) and (f) fracture surfaces of Udimet $720 \mathrm{Li}$ showing transgranular fracture under the loading waveform of $0.1-0-0.1-0$ and $1-1-1-1$, and mixed-trans-intergranular fracture at 1-120-1-1, respectively [100, 104].

\subsection{Effects of environmental damage}

\subsubsection{Environmental damage enhanced fatigue crack growth}

For those tests conducted in air at elevated temperatures $\left(>650^{\circ} \mathrm{C}\right)$, environmental damage (particularly oxygen-related damage) is found to enhance FCG significantly, especially when long dwell time/low loading frequency $(f<0.1 \mathrm{~Hz}$ in most PM Ni-based superalloiys) is employed $[4,5,11,12,21,85,88,89,92,109-118]$. This environmental damage enhanced FCG has also been observed in thermomechanical fatigue (TMF) crack growth tests in PM Ni-based superalloys [119-121], which is supported by the higher FCG rates associated with intergranular fractography under the in-phase (IP) loading conditions compared with out-of-phase (OP) testing associated with transgranular fractography, due to the increased temperature at peak stress and therefore increased time-dependent FCG. A few reviews of the interaction between environmental damage and fatigue in Ni-based superalloys can be found in $[4,21,109]$. In general, environmental damage enhanced FCG is a function of temperature $[11,12]$, oxygen partial pressure $[11,17,122]$, composition $[5,6,123]$, microstructure of the disc alloys $[11,12,97]$ and loading frequency $[19,86]$. As shown in Fig. 14, the FCG rates in 4 advanced disc superalloys (i.e. N18 [6, 10], Udimet 720Li [92], RR1000 [92] and LSHR [6, 11]) in air are usually one order of magnitude higher than that in vacuum under the same loading conditions. The microstructural characteristics of these 4 disc superalloys are summarised in Table 6. Enhanced FCG is usually associated with intergranular fracture features, which can be seen clearly in Fig. 15. Although creep damage is claimed to be partially responsible for these accelerated FCG processes and creep damage may also result in intergranular fracture $[20,21,106]$, the creep effect can be distinguished from the environmental damage effect by conducting fatigue tests in vacuum or low oxygen partial pressure conditions under different loading waveforms and frequencies $[10,11]$. As shown in Fig. 14, where there is no apparent increase in FCG rate due to a 20s dwell at the peak load in vacuum, it appears that the creep effect on FCG processes is much less significant compared 
with the effects of environmental damage. The environmental damage enhanced FCG is related to temperature and alloy composition and microstructure. The discrepancies in resistance to environmental damage enhanced FCG among different materials are more significant at higher temperature, as shown in Fig. 14. In addition, environmental damage enhanced FCG is related closely to the localised deformation at the crack tips which is strongly linked to the crack tip microstructure [12, 41, 122, 124-132]. As shown in Fig. 15, a transition from intergranular to mixed-inter-transgranular crack propagation is seen at $650{ }^{\circ} \mathrm{C}$ with a $20 \mathrm{~s}$ dwell at the peak load as $\Delta \mathrm{K}$ increases. Moreover, a transition from intergranular to transgranular crack growth is observed when a shorter dwell (i.e. 1s) was applied at the peak load as reported in [11], and this transition is more likely to occur in disc superalloys with coarser microstructures.

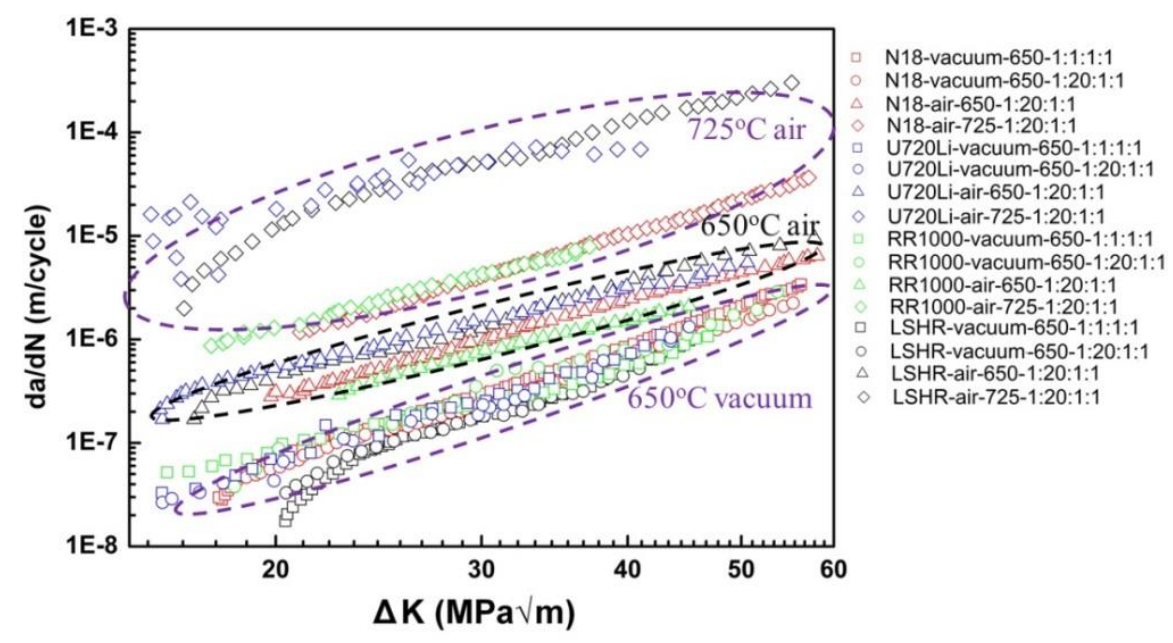

Fig. 14 Fatigue crack growth rates in four advanced turbine disc superalloys [23].

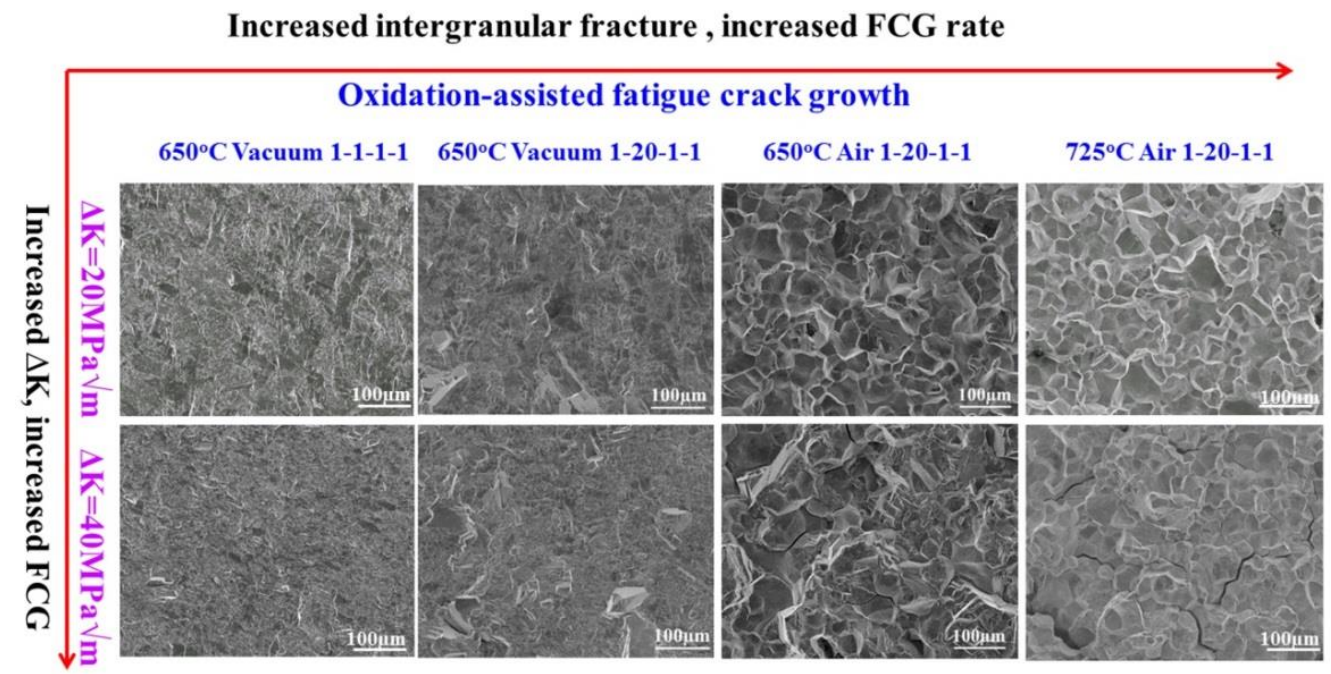

Fig. 15 Fractography of supersolvus heat treated LSHR alloy tested in vacuum and air at 650 
and $725^{\circ} \mathrm{C}$ using 1-1-1-1 and 1-20-1-1 loading waveform [11].

Table 6 Grain size and $\gamma^{\prime}$ size in the disc superalloys presented in Fig.14 [6, 10, 11, 92]

\begin{tabular}{|c|c|c|c|c|}
\hline & Grain size $(\mu \mathrm{m})$ & Primary $\gamma^{\prime}(\mu \mathrm{m})$ & Secondary $\quad \gamma^{\prime}(\mathrm{nm})$ & Tertiary $\gamma^{\prime}(\mathrm{nm})$ \\
\hline N18 & $8.7 \pm 4.7$ & $2.19 \pm 0.98$ & $188 \pm 112$ & 25 \\
\hline U720Li & $6.4 \pm 1.8$ & $1.99 \pm 0.9$ & 102 & 16 \\
\hline RR1000 & $7.4 \pm 2.8$ & $1.75 \pm 0.9$ & 140 & 18 \\
\hline LSHR & $36.1 \pm 18.1$ & N/A & $153 \pm 29$ & 15 \\
\hline
\end{tabular}

The environmental damage and its contribution to FCG is dependent on the microstructures of the investigated alloys and the stress-strain state at the crack tip, and is generally ascribed to the mechanism of dynamic embrittlement [78-80, 133] or SAGBO [11, $12,23,40,41,77,81,122,124,127,134-136]$. The former refers to the segregation of oxygen at the nanometre scale at the grain boundary ahead of the crack tip subjected to stress and a corresponding reduction in cohesive strength of the grain boundary, which then in turn accelerates intergranular FCG. The latter is associated with the accelerated formation of oxides along grain boundaries with the assistance of strain/stress at the crack tip. Enhanced intergranular FCG is achieved via the grain boundary oxide cracking due to its brittle nature and low fracture toughness. Detailed characterisation of the oxides at the crack tip in PM Ni-based superalloys shows that the oxide intrusions along grain boundaries normally consisted of layered oxides in the thermodynamic sequence of $\mathrm{CoO}, \mathrm{NiO}, \mathrm{Cr}_{2} \mathrm{O}_{3}, \mathrm{TiO}_{2}$ and $\mathrm{Al}_{2} \mathrm{O}_{3}[40,41,77,124]$, but variation of oxide compositions and structures at the crack tip also exist due to the complex compositions of PM Ni-based superalloys $[40,41,125,130]$. The degree of oxidation and/or the oxide intrusion ahead of the crack tip is dependent on the testing or in-service conditions, particularly the applied load and the local accumulated inelastic strain $[40,41,125,130]$. Although the applied load does not change the nature of the oxidising products, it enhances the oxidation process and produces a thicker oxide layer in comparison to the stress-free scenario $[128,129]$. The enhanced oxidation effect associated with the applied load/accumulated inelastic strain is rationalised by the accelerated diffusion of oxide-forming elements aided by stress or the high densities of dislocation and vacancies brought about by the accumulated strain $[129,137]$.

The dwell FCG behaviours in air observed in PM Ni-based superalloys at elevated 
temperatures are believed to be a consequence of the competing effects between environmental damage (i.e. SAGBO and dynamic embrittlement) and mechanical damage, which further depends on the accumulated strain/stress at the crack tip, the FCG rate and the delivery rate of oxygen to the crack tip. As a crack propagates, on the one hand, the increased local stress and strain at the crack tip can accelerate environmental damage process; on the other hand, the increased FCG rate reduces the available time for environmental damage to occur in a loading cycle. In addition, the delivery of oxygen to the propagating crack tip is hindered to some extent due to the tortuous nature of the crack path and the crack closure effect. This is supported by the results reported in [17], where significant environmental damage (i.e. oxidation) was found on the polished side surface of a single edge notch bending specimen of LSHR alloy, but no evident oxides were observed at the fast propagating crack tip in the bulk materials. Under the dwell-fatigue conditions, the oxides that form during the dwell period may build up at the crack tip or may be subjected to a dynamic oxide formation-cracking cycle depending on the $\Delta \mathrm{K}$ level at the crack tip, as illustrated in Li's study [12]. However, in the scenario of no oxide cracking during the dwell period at the low $\Delta \mathrm{K}$ level or in the scenario of dynamic oxide formation and cracking during the dwell period at the relatively high $\Delta \mathrm{K}$ level, the contribution of oxidation to $\mathrm{FCG}$ increases with $\Delta \mathrm{K}$ level until a transitional FCG rate is reached. Beyond this transitional FCG rate, there is insufficient time at the crack tip for evident oxidation to occur, and the oxidation effect diminishes. With further increases in FCG rate, then the mechanisms contributing to intergranular FCG may be dominated by dynamic embrittlement. As the dynamic embrittlement mechanism is mainly linked to stress-assisted oxygen diffusion along the grain boundary within the nanometre scale $[78,79]$, it is expected that the contribution of dynamic embrittlement to FCG is closely related to local stress/strain acting on the grain boundaries at the crack tip and is increased with the applied stress/strain at the crack tip as indicated in an analytical model proposed by Bika [80], where only one-dimensional diffusion of oxygen along the grain boundary is considered. At the higher $\Delta \mathrm{K}$ level, it is feasible for repeated processes of dynamic embrittlement-grain boundary cracking to occur, resulting in overall rapid FCG. With further increases in FCG rate, the mechanical damage which is mainly determined by the far field applied stress, the crack length and the strength of the investigated material may then start to 
outstrip the environmental damage ahead of the crack tip, giving rise to transgranular FCG. This is supported by the observations of the predominantly intergranular FCG at $\Delta \mathrm{K}$ of 20 $\mathrm{MPa} \sqrt{\mathrm{m}}$ converting to transgranular FCG at $\Delta \mathrm{K}$ of $40 \mathrm{MPa} \sqrt{\mathrm{m}}$ at $650{ }^{\circ} \mathrm{C}$ under a 1-1-1-1 load waveform in the CG LSHR alloy variant [11].

\subsubsection{Threshold fatigue crack growth behaviours}

Apart from the FCG behaviour in the Paris regime, environmental damage also influences the threshold FCG behaviors in PM disc superalloys. Gabb et al. [138, 139] investigated the high temperature cyclic FCG threshold behaviours of two advanced disc alloys (i.e. LSHR and ME3). They studied the unusual crossover effect in the near-threshold region of these type of alloys where conditions which produce higher FCG rates in the Paris regime, produce higher resistance to FCG in the near threshold regime. It was shown that this crossover effect is associated with a sudden change in the fatigue failure mode from a predominantly transgranular mode in the Paris regime to a fully intergranular mode in the threshold FCG region. What is especially striking is that the predominant transgranular failure mode is associated with the faster FCG rates of the Paris regime while the fully intergranular failure mode occurs at the onset of transition to much slower near-threshold FCG regime and continues throughout the crack growth in the threshold region. This is in contrast to the usual trends observed during FCG in superalloys where the intergranular failure mode is associated with much faster FCG rates than transgranular failure mode. As shown in Fig.16, both ME3 and LSHR tests which exhibited mostly transgranular failure and did not exhibit a sudden change in the failure mode, resulted in considerably lower threshold stress intensities than their counterparts which did experience an transgranular to intergranular failure mode transition. Since all the non-transition tests were performed under conditions which minimize the effect of environment, i.e. lower temperature, vacuum or high frequency, the results provide additional evidence that the observed sudden failure mode transition is due to an environmentally driven mechanism. 

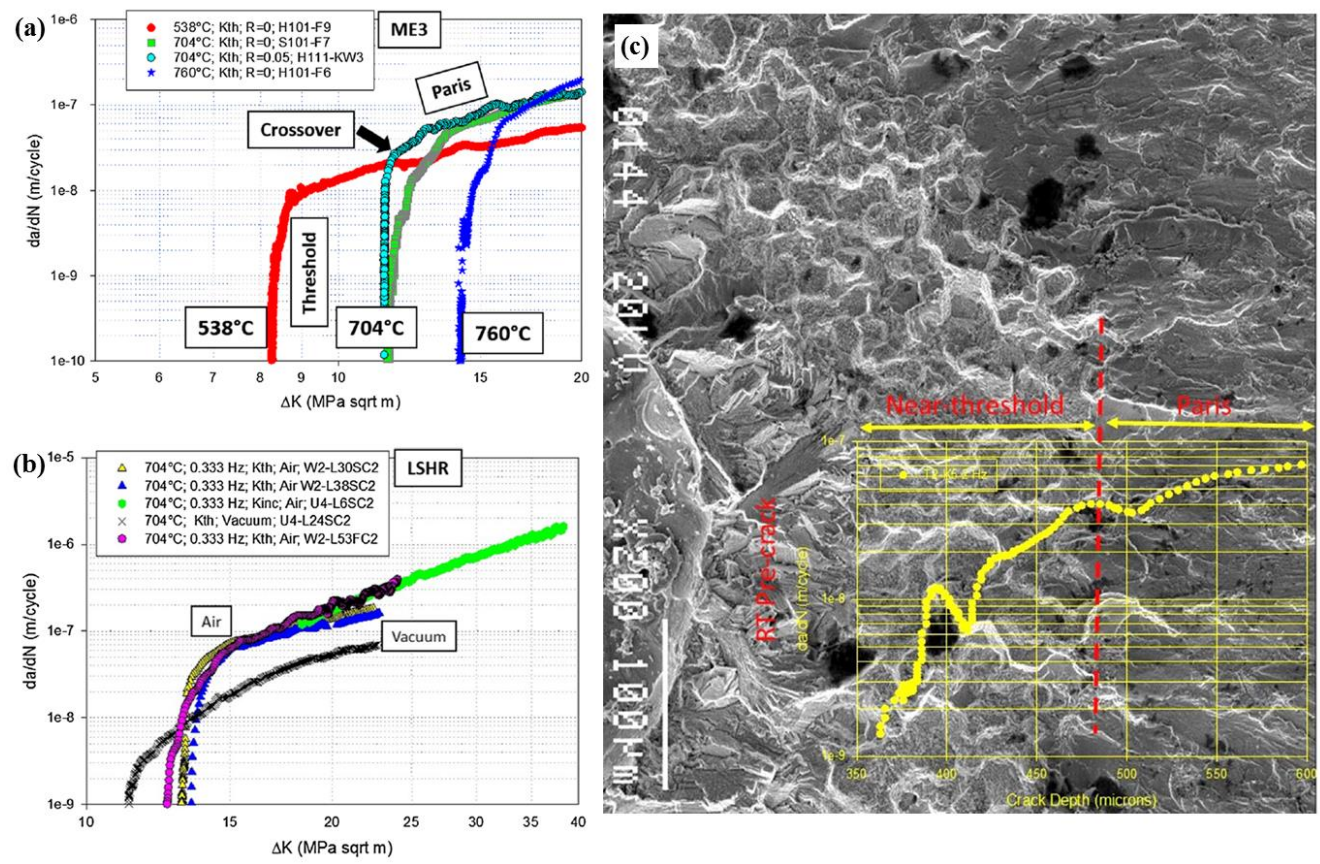

Fig. 16 The crossover effect between threshold and Paris regimes (a) ME3 at various temperatures and (b) LSHR in air and vacuum at $704^{\circ} \mathrm{C}$, (c) LSHR FCG rates superimposed on the SEM fractograph. Intergranular failure corresponds closely with near-threshold regime $[138,139]$

\subsubsection{Characterisation of deformation at the crack tip}

As mentioned previously, the operation of SAGBO or dynamic embrittlement is closely related to oxygen diffusion in the strain/stress field around the crack tip $[4,40,77,79,127$, 140]. To further clarify the mechanism of stress/strain assisted environmental damage at the propagating crack tip, it is necessary to quantify the plastic deformation. As outlined in an important early review by Ghonem et al [140], the oxidation process is related to the degree of homogeneity of plastic deformation and associated slip density at the crack tip. For conditions promoting homogeneous plastic deformation, with a high degree of slip density, the environmental damage contribution is shown to be limited, thus permitting the dominance of cyclic damage effects which are characterized by a transgranular FCG mode and a lower FCG rate. Under conditions leading to inhomogeneous plastic deformation and lower slip density, the crack tip damage is described in terms of grain boundary oxidation and related intergranular fracture mode.

Although the relationship between the deformation homogeneity and the FCG mode may 
still be open to discussion, characterisation of strain/stress on a grain level as a consequence of microstructural inhomogeneity (e.g. grain size, precipitate size and grain orientation) at the crack tip is essential and is believed to be critical to assess and understand the role of oxygen in enhanced FCG behaviours. The challenge lies in obtaining the localised heterogeneous deformation at elevated temperatures with high spatial resolution, which rules out the usage of long established techniques such as strain gauges or extensometers. DIC has been developed to map strains across surfaces [141], and some efforts have been made to produce fine speckle patterns via Au particle sputtering [142, 143], etching of intrinsic microstructures in Ni-based superalloy such as secondary $\gamma^{\prime}[144,145]$, and electron beam lithography of hafnium oxide [146, 147], in order to improve the spatial resolution of obtained strain field and to investigate the deformation at the grain and/or subgrain level. Alternatively, the localised strain at the crack tip can be characterised by high resolution EBSD which is developed to assess strain on a grain level by analysing Kikuchi pattern variation/degradation after a post-test characterisation [25, 148, 149].

Carroll and Tong et al. have employed DIC to characterize the full-field strain distribution at the crack tip $[131,132,150-153]$ and detailed the application of DIC in full-field characterisation of crack tip deformation and FCG in a recent review [151]. Through these full field DIC analyses of crack tip deformation, inhomogeneous plastic strain fields associated with FCG are captured at both macro-scale and micro-scale. The macro-scale deformation inhomogeneity is manifested by the plastic wake contained high strain regions in the form of asymmetric lobes associated with past crack tip plastic zones, and the link between the macro-scale deformation inhomogeneity and oxidation is revealed by the oxides formed in these regions which take on an upside-down "V" shape at the crack tip as shown in reference [17]. Whereas the micro-scale deformation inhomogeneity is reflected by the varying plastic strain from grain to grain and the strain localisation in slip bands within grains and on twin and grain boundaries, and the link between the micro-scale deformation inhomogeneity and oxidation is disclosed by the oxides forming along certain grain boundaries and slip bands $[40,42]$. There is no doubt that the plastic deformation at the crack tip has a significant influence on oxidation processes, but quantification assessment of these influences at the crack tip is still rare, especially with respect to the role of plastic deformation 
in oxygen diffusion. Further study of the deformation-dependant oxygen diffusion and oxidation processes at the crack tip is necessary to get an in-depth understanding of the environmental damage enhanced FCG behaviours, and thus high resolution full field strain measurement at the crack tip is essential.

\section{Perspectives and concluding remarks}

Fatigue of materials is a well-established and important research area with a long history. FCG behaviours have been extensively studied, especially after the emergence of the damage tolerance design concept which designs engineering components against FCG rates as a function of crack driving force. Although the FCG mechanisms have been extensively investigated under various loading conditions in PM superalloys with various microstructures, clear understanding of the FCG mechanisms still requires separation of the inter-dependent effects of fatigue, creep and environmental damage on FCG and to clarify the interaction between fatigue, creep and environmental damage. It is also necessary to understand the dependence of FCG on individual microstructural features and grain boundary precipitates such as carbides. These will be useful to guide the optimisation of manufacturing processes of PM Ni-based superalloys with excellent FCG resistance and to develop more advanced and microstructure-sensitive mechanistic models for accurate FCG life prediction. In addition, measurement of FCG rates under TMF conditions and investigation of effects of stress/temperature phasing on FCG is also desirable. TMF crack growth in PM Ni-Based superalloys is an emerging field. The effects of phase angle on TMF crack growth behaviours in two grain size variants of RR1000 were initially investigated $[121,154,155]$ and a transition from intergranular to transgranular growth between low and high phase angle tests as a result of the onset of high temperature damage mechanisms (time-dependent FCG behaviours) is identified based on the fractography analysis. Similar to isothermal experiments, the finer grain size is related to higher TMF crack growth rate over all phase angles, especially under the IP loading, as there is less microstructural resistance to FCG. However, in general, studies with regards to TMF crack growth mechanisms in PM Ni-based superalloys are quite limited, and further studies are needed. This is key in providing quasi 
in-service condition FCG data so that more accurate predictions can be made using appropriate phenomenological and mechanistic FCG models for PM superalloy turbine disc lifing assessment $[120,156]$.

Conventionally, FCG rates have been measured by DCPD method and/or surface based 2D microscopic observation. These methods usually underestimate the crack length, especially in the case where oxygen-assisted FCG is dominant, due to crack branching at the propagating intergranular crack tip or micro-cracking processes ahead of the crack tip with interlinked uncracked ligaments $[17,116]$. Compared with conventional assessments, recent development of X-ray computed tomography and diffraction contrast tomography alongside in-situ fatigue tests may provide a 3D and/or 4D assessment of FCG behaviours in terms of crack morphology and grain structures at higher resolution without damaging the specimens, as shown in Fig. 17. In addition, secondary cracks around crack tips can be captured in better 3D detail with tomography [17], and will be helpful to assess stress redistribution at the crack tip and stress relaxation, which is closely related to the environmental damage at the crack tip and FCG. These 3D and/or 4D assessments therefore can provide more data-rich results and a more complete view of FCG behaviours $[49,50,157]$. Such 3D datasets can be used to construct image-based models and hence could potentially be imported into local FE analysis models to more accurately simulate FCG behaviours with incorporated visco-plasticity and/or crystal plasticity material constitutive models.

The FCG behaviours in PM Ni-based superalloys are closely related to the damage arising from fatigue, creep and environmental attack such as oxidation at the crack tip. Understanding more fully the nature of the interactions between fatigue, creep and environmental damage processes at the crack tip is necessary to develop microstructure-sensitive mechanistic FCG models and a crack advancement criterion which combines the influences of fatigue-creep-environmental damage, to yield a cost-effective and safe prediction of the FCG performance of PM Ni-based superalloys and their components. Such models will require characterisation of environmental damage and deformation microstructures as well as quantification of the plastic deformation at the crack tip. The nature of environmental damage at the crack tip and the oxygen diffusion processes within the plastic zone ahead of the crack tip should be further studied, to quantitatively describe the 
environmental damage in terms of thermodynamics and kinetics. Characterisation of strain/stress ahead of the crack tip at a grain level and the study of the influence of microstructural inhomogeneity on the localised deformation should clarify the strain/stress-assisted oxygen diffusion processes and diffusion of the relevant oxide-forming elements. The measured strain field at the crack tip can provide valuable validation data for any CPFE simulation of deformation at the crack tip. These will then allow quantification of the relation between microstructural features, deformation processes, environmental damage and the local FCG behaviour and provide necessary inputs and validation data for robust FCG modelling in PM Ni-based superalloys.

(a)

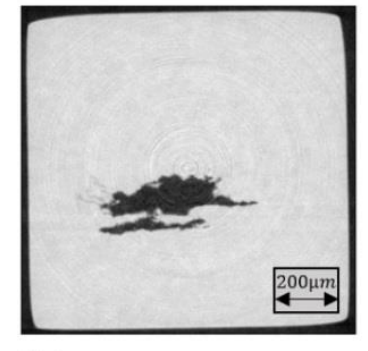

(b)

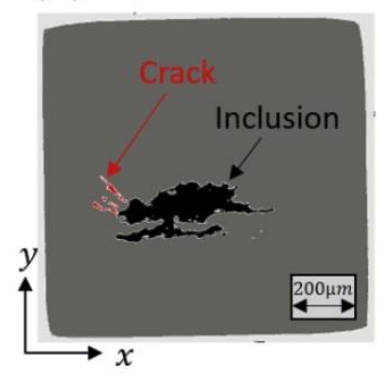

(c)

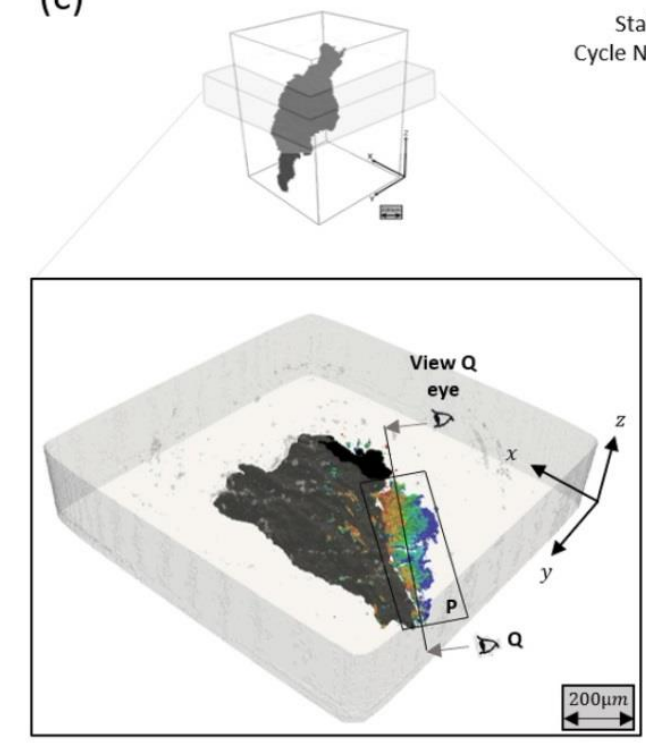

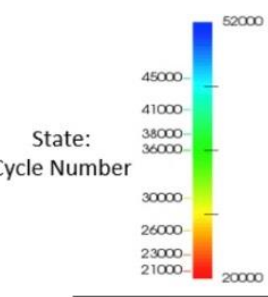
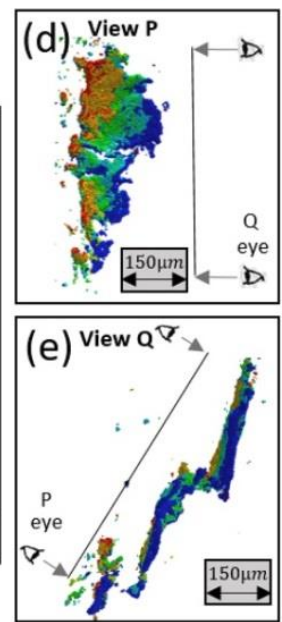

Fig. 17 (a) Cross-section from $\mu$-CT reconstruction juxtaposed with (b) results of segmentation of the different phases: matrix, inclusion, and crack. (c) Specimen with inset showing the crack growing from the inclusion between $20 \mathrm{k}$ and $52 \mathrm{k}$ cycles. (d) View of the crack along plane $\mathrm{P}$ (as defined in c), displaying crack growth relative to the cycle number. (e) View of the crack from vantage point Q (as defined in c), showing a bridge in the crack structure [49].

In summary, FCG in PM Ni-based superalloys is a complicated function of microstructural features, temperature, environment and loading conditions, and the synergistic 
effects of fatigue, creep and environmental damage make the FCG processes quite complicated. In general, coarse grained structures show better FCG resistance, and coarser $\gamma^{\prime}$ is generally associated with more evident stress relaxation at the crack tip and thereby provides relatively better FCG resistance under dwell fatigue conditions. Compared with environmental damage, creep makes limited contribution to FCG rates in PM Ni-based superalloys. The environmental damage arising from SAGBO and/or dynamic embrittlement, which is closely related to plastic deformation and microstructures at the crack tip, can accelerate FCG by one or two orders of magnitude. However, due to synergistic effects, the individual contribution of grain size, grain orientation, $\gamma^{\prime}$ precipitates etc and the individual contribution of fatigue, creep and environmental damage to FCG is still difficult to separate and to quantify, which requires further study before fully descriptive models of the process can be initialised and validated. [145]

\section{Acknowledgement}

RJ and YDS would like to thank the National Science and Technology Major Project (2017-VI-0008-0078; 2017-IV-0004-0041), National Natural Science Foundation of China (No. 51805251; 11872204), the Natural Science Foundation of Jiangsu Province (No. BK20180434), Nanjing University of Aeronautics and Astronautics (No. 1002-YAH18002) and Key Laboratory of Aero-engine Thermal Environment and Structure, Ministry of Industry and Information Technology (CEPE2018008) for financial support. PAS would like to thank the Engineering and Physical Sciences Research Council (Grant EP/K027271/1; EP/M000710/1) in the UK for financial support. Thanks are also due to Prof. Liguo Zhao at Loughborough University, Dr. Tim Gabb at NASA Glenn Research centre, Dr. Mark Hardy at Rolls-Royce, Dr. Gordon McColvin at GE Power, Dr. Matthew Lunt at Defence Science and Technology Laboratory, Prof. Scott Lockyer and Dr. Katherine Soady at Uniper Technologies Ltd, Prof. Yiwen Zhang and Prof Jiantao Liu at the Central Iron \& Steel Research Institute for useful discussions. 


\section{References}

[1] Reed RC. The Superalloys: Fundamental and Applications, Cambridge University Press; 2006.

[2] Pollock TM, Van der Ven A. The evolving landscape for alloy design. MRS Bulletin 2019; 44:238-46.

[3] Pollock TM, Tin S. Nickel-Based Superalloys for Advanced Turbine Engines: Chemistry, Microstructure and Properties. Journal of Propulsion and Power 2006; 22:361-74.

[4] Pineau A, Antolovich SD. High temperature fatigue of nickel-base superalloys - A review with special emphasis on deformation modes and oxidation. Engineering Failure Analysis 2009; 16:2668-97. [5] Pang HT, Hardy MC, Hide N, Wilcock IM, Henderson MB, Reed PAS. Comparison of fatigue crack propagation in nickel base superalloys RR1000 and Udimet 720Li. Materials Science and Technology 2016; 32:22-39.

[6] Everitt S, Jiang R, Gao N, Starink MJ, Brooks JW, Reed PAS. Comparison of fatigue crack propagation behaviour in two gas turbine disc alloys under creep-fatigue conditions: evaluating microstructure, environment and temperature effects. Materials Science and Technology 2013; 29:781-7.

[7] Christofidou KA, Hardy MC, Li H-Y, Argyrakis C, Kitaguchi H, Jones NG, et al. On the Effect of $\mathrm{Nb}$ on the Microstructure and Properties of Next Generation Polycrystalline Powder Metallurgy Ni-Based Superalloys. Metall and Mat Trans A 2018; 49:3896-3907.

[8] Pineau A, McDowell DL, Busso EP, Antolovich SD. Failure of metals II: Fatigue. Acta Materialia 2016; 107:484-507.

[9] Pineau A, Antolovich SD. High temperature fatigue: behaviour of three typical classes of structural materials. Materials at High Temperatures 2015; 32:298-317.

[10] Jiang R, Everitt S, Gao N, Soady K, Brooks JW, Reed PAS. Influence of oxidation on fatigue crack initiation and propagation in turbine disc alloy N18. International Journal of Fatigue 2015; 75:89-99.

[11] Jiang R, Everitt S, Lewandowski M, Gao N, Reed PAS. Grain size effects in a Ni-based turbine disc alloy in the time and cycle dependent crack growth regimes. International Journal of Fatigue 2014; 62:217-27.

[12] Li HY, Sun JF, Hardy MC, Evans HE, Williams SJ, Doel TJA, et al. Effects of microstructure on high temperature dwell fatigue crack growth in a coarse grain PM nickel based superalloy. Acta Materialia 2015; 90:355-69.

[13] Hu D, Wang T, Ma Q, Liu X, Shang L, Li D, et al. Effect of inclusions on low cycle fatigue lifetime in a powder metallurgy nickel-based superalloy FGH96. International Journal of Fatigue 2019; 118:237-48.

[14] Stinville JC, Martin E, Karadge M, Ismonov S, Soare M, Hanlon T, et al. Fatigue deformation in a polycrystalline nickel base superalloy at intermediate and high temperature: Competing failure modes. Acta Materialia 2018; 152:16-33.

[15] Telesman J, Gabb TP, Ghosn LJ, Gayda J. Effect of notches on creep-fatigue behavior of a P/M nickel-based superalloy. International Journal of Fatigue 2016; 87:311-25.

[16] Gabb TP, Gayda J, Telesman J, Ghosn LJ, Garg A. Factors influencing dwell fatigue life in notches of a powder metallurgy superalloy. International Journal of Fatigue 2013; 48:55-67.

[17] Jiang R, Bull DJ, Proprentner D, Shollock B, Reed PAS. Effects of oxygen-related damage on 
dwell-fatigue crack propagation in a $\mathrm{P} / \mathrm{M}$ Ni-based superalloy: From $2 \mathrm{D}$ to $3 \mathrm{D}$ assessment. International Journal of Fatigue 2017; 99, Part 1:175-86.

[18] Turan D, Hunt D, Knowles DM. Dwell time effect on fatigue crack growth of RR1000 superalloy. Materials Science and Technology 2007; 23:183-8.

[19] Dahal J, Maciejewski K, Ghonem H. Loading frequency and microstructure interactions in intergranular fatigue crack growth in a disk Ni-based superalloy. International Journal of Fatigue 2013; 57:93-102.

[20] Maciejewski K, Dahal J, Sun Y, Ghonem H. Creep-Environment Interactions in Dwell-Fatigue Crack Growth of Nickel Based Superalloys. Metall and Mat Trans A 2014; 45:2508-21.

[21] Leo Prakash DG, Walsh MJ, Maclachlan D, Korsunsky AM. Crack growth micro-mechanisms in the IN718 alloy under the combined influence of fatigue, creep and oxidation. International Journal of Fatigue 2009; 31:1966-77.

[22] Antolovich SD. Microstructural aspects of fatigue in Ni-base superalloys. Philosophical Transactions of the Royal Society of London A: Mathematical, Physical and Engineering Sciences $2015 ; 373$.

[23] Jiang R, Reed PAS. Critical Assessment 21: oxygen-assisted fatigue crack propagation in turbine disc superalloys. Materials Science and Technology 2016; 32:401-6.

[24] Pang HT, Reed PAS. Microstructure effects on high temperature fatigue crack initiation and short crack growth in turbine disc nickel-base superalloy Udimet 720Li. Materials Science and Engineering: A 2007; 448:67-79.

[25] Zhang T, Jiang J, Shollock BA, Britton TB, Dunne FPE. Slip localization and fatigue crack nucleation near a non-metallic inclusion in polycrystalline nickel-based superalloy. Materials Science and Engineering: A 2015; 641:328-39.

[26] Miao G, Yang X, Shi D. Competing fatigue failure behaviors of Ni-based superalloy FGH96 at elevated temperature. Materials Science and Engineering: A 2016; 668:66-72.

[27] Stephens RR, Grabowski L, Hoeppner DW. The effect of temperature on the behaviour of short fatigue cracks in Waspaloy using an in situ SEM fatigue apparatus. International Journal of Fatigue $1993 ; 15: 273-82$.

[28] Miao J, Pollock TM, Wayne Jones J. Crystallographic fatigue crack initiation in nickel-based superalloy Rene88DT at elevated temperature. Acta Materialia 2009;57:5964-74.

[29] Pang HT, Reed PAS. Effects of microstructure on room temperature fatigue crack initiation and short crack propagation in Udimet 720Li Ni-base superalloy. International Journal of Fatigue 2008; 30:2009-2020.

[30] Jiang R, Karpasitis N, Gao N, Reed PAS. Effects of microstructures on fatigue crack initiation and short crack propagation at room temperature in an advanced disc superalloy. Materials Science and Engineering: A 2015; 641:148-59.

[31] Mei Z, Krenn C, Morris J. Initiation and growth of small fatigue cracks in a Ni-base superalloy. Metallurgical and Materials Transactions A 1995; 26:2063-73.

[32] Menon MN, Reimann WH. Low-cycle fatigue-crack initiation study in René 95. Journal of Materials Science 1975; 10:1571-81.

[33] Sudbrack CK, Draper SL, Gorman TT, Telesman J, Gabb TP, Hull DR. Oxidation and the Effects of High Temperature Exposures on Notched Fatigue Life of an Advanced Powder Metallurgy Disk Superalloy. Superalloys 2012: John Wiley \& Sons, Inc.; 2012. p. 863-72.

[34] Timothy P. Gabb JG, and Jack Telesman. Thermal and Mechanical Property Characterization of 
the Advanced Disk Alloy LSHR. NASA/TM-2005-213645 2005.

[35] Bache MR, O'Hanlon J, Child DJ, Hardy MC. High temperature fatigue behaviour in an advanced nickel based superalloy: The effects of oxidation and stress relaxation at notches. Theoretical and Applied Fracture Mechanics 2016; 84:64-71.

[36] Jiang R, Gao N, Reed PAS. Influence of orientation-dependent grain boundary oxidation on fatigue cracking behaviour in an advanced Ni-based superalloy. Journal of Material Sciences 2015; 50:4379-4386.

[37] Cruchley S, Taylor MP, Li HY, Evans HE, Bowen P, Child DJ, et al. Effect of prior oxidation on high cycle fatigue performance of RR1000 and role of oxidation in fatigue crack initiation. Materials at High Temperatures 2015; 32:68-73.

[38] Gao Y, Stölken JS, Kumar M, Ritchie RO. High-cycle fatigue of nickel-base superalloy René 104 (ME3): Interaction of microstructurally small cracks with grain boundaries of known character. Acta Materialia 2007; 55:3155-3167.

[39] Luo J, Bowen P. Small and long fatigue crack growth behaviour of a PM Ni-based superalloy, Udimet 720. International Journal of Fatigue 2004; 26:113-24.

[40] Jiang R, Proprentner D, Callisti M, Shollock B, Hu XT, Song YD, et al. Role of oxygen in enhanced fatigue cracking in a PM Ni-based superalloy: Stress assisted grain boundary oxidation or dynamic embrittlment? Corrosion Science 2018; 139:141-54.

[41] Kitaguchi HS, Li HY, Evans HE, Ding RG, Jones IP, Baxter G, et al. Oxidation ahead of a crack tip in an advanced Ni-based superalloy. Acta Materialia 2013; 61:1968-81.

[42] Jiang R, Pierron F, Octaviani S, Reed PAS. Characterisation of strain localisation processes during fatigue crack initiation and early crack propagation by SEM-DIC in an advanced disc alloy. Materials Science and Engineering: A 2017; 699:128-44.

[43] Goto M, M. Knowles D. Initiation and propagation behaviour of microcracks in Ni-base superalloy Udimet 720 Li. Engineering Fracture Mechanics 1998; 60:1-18.

[44] Pang HT, Reed PAS. Fatigue crack initiation and short crack growth in nickel-base turbine disc alloys - the effects of microstructure and operating parameters. International Journal of Fatigue 2003; 25:1089-99.

[45] Miao J, Pollock TM, Wayne Jones J. Crystallographic fatigue crack initiation in nickel-based superalloy René 88DT at elevated temperature. Acta Materialia 2009; 57:5964-74.

[46] Musinski WD, McDowell DL. Simulating the effect of grain boundaries on microstructurally small fatigue crack growth from a focused ion beam notch through a three-dimensional array of grains. Acta Materialia 2016; 112:20-39.

[47] Gockel BT, Caton MJ, Jha SK, Szczepanski CJ, Rosenberger AH, Burba ME. Developing the Capability to Monitor Small Fatigue Crack Growth Under Elevated Temperature, Ultra-High Vacuum Conditions. Experimental Mechanics 2015; 55:951-61.

[48] Maire E. Withers PJ. Quantitative X-ray tomography. International Materials Reviews 2014; 59:1-43.

[49] Naragani DP, Shade PA, Kenesei P, Sharma H, Sangid MD. X-ray characterization of the micromechanical response ahead of a propagating small fatigue crack in a Ni-based superalloy. Acta Materialia 2019; 179:342-59.

[50] Jiménez M, Ludwig W, Gonzalez D, Molina-Aldareguia JM. The role of slip transfer at grain boundaries in the propagation of microstructurally short fatigue cracks in Ni-based superalloys. Scripta Materialia 2019; 162:261-5. 
[51] Findley KO, Evans JL, Saxena A. A critical assessment of fatigue crack nucleation and growth models for Ni-and Ni,Fe-based superalloys. International Materials Reviews 2011; 56:49-71.

[52] Miao J, Pollock TM, Wayne Jones J. Microstructural extremes and the transition from fatigue crack initiation to small crack growth in a polycrystalline nickel-base superalloy. Acta Materialia 2012; 60:2840-54.

[53] Alam Z, Eastman, D. , Weber, G. , Ghosh, S. , Ghosh, S. and Hemker, K. Microstructural Aspects of Fatigue Crack Initiation and Short Crack Growth in René 88DT. In Superalloys 2016 (eds M. Hardy, E. Huron, U. Glatzel, B. Griffin, B. Lewis, C. Rae, V. Seetharaman and S. Tin). Superalloys 2016. p. 561-8.

[54] Gao Y, Ritchie R, Kumar M, Nalla R. High-cycle fatigue of nickel-based superalloy ME3 at ambient and elevated temperatures: Role of grain-boundary engineering. Metallurgical and Materials Transactions A 2005; 36:3325-33.

[55] Zhai T, Wilkinson AJ, Martin JW. A crystallographic mechanism for fatigue crack propagation through grain boundaries. Acta Materialia 2000; 48:4917-27.

[56] Marx M, Schaef W, Vehoff H. Interaction of short cracks with the local microstructure. Procedia Engineering 2010; 2:163-71.

[57] Schaef W, Marx M, Vehoff H, Heckl A, Randelzhofer P. A 3-D view on the mechanisms of short fatigue cracks interacting with grain boundaries. Acta Materialia 2011; 59:1849-61.

[58] Schaef W, Marx M. A numerical description of short fatigue cracks interacting with grain boundaries. Acta Materialia 2012; 60:2425-36.

[59] Abuzaid WZ, Sangid MD, Carroll JD, Sehitoglu H, Lambros J. Slip transfer and plastic strain accumulation across grain boundaries in Hastelloy X. Journal of the Mechanics and Physics of Solids 2012; 60:1201-20.

[60] Jiang J, Yang J, Zhang T, Zou J, Wang Y, Dunne FPE, et al. Microstructurally sensitive crack nucleation around inclusions in powder metallurgy nickel-based superalloys. Acta Materialia 2016; 117:333-44.

[61] Karabela A, Zhao LG, Lin B, Tong J, Hardy MC. Oxygen diffusion and crack growth for a nickel-based superalloy under fatigue-oxidation conditions. Materials Science and Engineering: A 2013; 567:46-57.

[62] Lin B, Zhao LG, Tong J, Christ HJ. Crystal plasticity modeling of cyclic deformation for a polycrystalline nickel-based superalloy at high temperature. Materials Science and Engineering: A 2010; 527:3581-7.

[63] Zhang ZJ, Zhang P, Li LL, Zhang ZF. Fatigue cracking at twin boundaries: Effects of crystallographic orientation and stacking fault energy. Acta Materialia 2012; 60:3113-27.

[64] Crawford D, Was G. The Role of grain boundary misorientation in intergranular cracking of $\mathrm{Ni}-16 \mathrm{Cr}-9 \mathrm{Fe}$ in $360^{\circ} \mathrm{C}$ argon and high-Purity water. Metallurgical Transactions A 1992; 23:1195-206.

[65] Palumbo G, Lehockey E, Lin P. Applications for grain boundary engineered materials. Journal of the Minerals, Metals and Materials Society 1998; 50:40-3.

[66] Brandon DG. The structure of high-angle grain boundaries. Acta Metallurgica 1966; 14:1479-84.

[67] Li J, Dillon SJ, Rohrer GS. Relative grain boundary area and energy distributions in nickel. Acta Materialia 2009; 57:4304-11.

[68] Olmsted DL, Foiles SM, Holm EA. Survey of computed grain boundary properties in face-centered cubic metals: I. Grain boundary energy. Acta Materialia 2009; 57:3694-703.

[69] Pang HT, Reed PAS. Effects of microstructure on room temperature fatigue crack initiation and 
short crack propagation in Udimet 720Li Ni-base superalloy. International Journal of Fatigue 2008; 30:2009-20.

[70] Holzapfel C, Schäf W, Marx M, Vehoff H, Mücklich F. Interaction of cracks with precipitates and grain boundaries: Understanding crack growth mechanisms through focused ion beam tomography. Scripta Materialia 2007; 56:697-700.

[71] Mello AW, Nicolas A, Sangid MD. Fatigue strain mapping via digital image correlation for Ni-based superalloys: The role of thermal activation on cube slip. Materials Science and Engineering: A 2017; 695:332-41.

[72] Xie XS, Zhang L, Zhang MC, Dong JX, Bain K, Micro-mechanical behavior study of non-metallic inclusions in P/M disk superalloy Rene'95. In: K. A. Green, T. M. Pollock, H. Harada, T. E. Howson, R. C. Reed, J. J. Schirra, and S. Walston, editors. Superalloys 2004. Warrendale (PA): The Minerals, Metals \& Materials Society; 2004. p. 451-458.

[73] Artamonov MA, Trunkin IN, Ovcharov AV, Vasiliev AL, The investigation of the of fatigue crack growth mechanism in powder metallurgy Ni-based superalloy. Procedia Structural Integrity 2019; 23:251-256.

[74] Caton MJ, Jha SK. Small fatigue crack growth and failure mode transitions in a Ni-base superalloy at elevated temperature. International Journal of Fatigue 2010; 32:1461-72.

[75] Sansoz F, Brethes B, Pineau A. Growth of short fatigue cracks from stress concentrations in N18 superalloy. In: Rémy L, Petit J, editors. European Structural Integrity Society: Elsevier; 2002. p. 287-96.

[76] Sansoz F, Brethes B, Pineau A. Propagation of short fatigue cracks from notches in a Ni base superalloy: experiments and modelling. Fatigue \& Fracture of Engineering Materials \& Structures 2002; 25:41-53.

[77] Evans HE, Li HY, Bowen P. A mechanism for stress-aided grain boundary oxidation ahead of cracks. Scripta Materialia 2013; 69:179-82.

[78] Krupp U, Kane WM, Laird C, McMahon CJ. Brittle intergranular fracture of a Ni-base superalloy at high temperatures by dynamic embrittlement. Materials Science and Engineering: A 2004; 387389:409-13.

[79] Pfaendtner JA, McMahon Jr CJ. Oxygen-induced intergranular cracking of a Ni-base alloy at elevated temperatures - an example of dynamic embrittlement. Acta Materialia 2001; 49:3369-77.

[80] Bika D, McMahon Jr CJ. A model for dynamic embrittlement. Acta Metallurgica et Materialia 1995; 43:1909-16.

[81] Jiang R, Gao N, Ward M, Aslam Z, Walker JC, Reed PAS. Effects of Oxidation on Fatigue Crack Initiation and Propagation in an Advanced Disk Alloy. Superalloys 2016: Proceedings of the 13th International Symposium on Superalloys, Edited by: Mark Hardy, Eric Huron, Uwe Glatzel, Brian Griffin, Beth Lewis, Cathie Rae, Venkat Seetharaman, and Sammy Tin TMS (The Minerals, Metals \& Materials Society).

[82] Krupp U. Fatigue Crack Propagation in Metals and Alloys. betz-druck GmbH, Darmstadt 2007.

[83] Elber W. Fatigue crack closure under cyclic tension. Engineering Fracture Mechanics 1970; 2:37-45.

[84] Liaw PK. Overview of Crack Closure at near-Threshold Fatigue Crack Growth Levels. Proc Mechanics of Fatigue Crack Closure, JC Newman Jr, W Elber (Eds), ASTM STP 982 (1988) 621988.

[85] Tong J, Dalby S, Byrne J, Henderson MB, Hardy MC. Creep, fatigue and oxidation in crack growth in advanced nickel base superalloys. International Journal of Fatigue 2001; 23:897-902. 
[86] Tong, Byrne. Effects of frequency on fatigue crack growth at elevated temperature. Fatigue \& Fracture of Engineering Materials \& Structures 1999; 22:185-93.

[87] Schulz F, Li HY, Kitaguchi H, Child D, Williams S, Bowen P. Influence of Tertiary Gamma Prime $\left(\gamma^{\prime}\right)$ Size Evolution on Dwell Fatigue Crack Growth Behavior in CG RR1000. Metallurgical and Materials Transaction A 2018; 49:3874-84.

[88] Maciejewski K, Ghonem H. Influence of continuum precipitates on intergranular fatigue crack growth of a P/M nickel-based superalloy. Materials Science and Engineering: A 2013; 560:439-49.

[89] Maciejewski K, Ghonem H. Relative contributions of secondary and tertiary $\gamma^{\prime}$ precipitates to intergranular crack growth resistance in IN100 alloy. Superalloys 2012, 2012:421-30.

[90] Gayda J, Miner RV. The effect of microstructure on $650{ }^{\circ} \mathrm{C}$ fatigue crack growth in P/M astroloy. Metallurgical Transaction A 1983; 14:2301-8.

[91] Pang HT, Reed PAS. Microstructure variation effects on room temperature fatigue threshold and crack propagation in Udimet 720Li Ni-base superalloy. Fatigue \& Fracture of Engineering Materials \& Structures 2009; 32:685-701.

[92] Everitt S, Starink MJ, Pang HT, Wilcock IM, Henderson MB, Reed PAS. A comparison of high temperature fatigue crack propagation in various subsolvus heat treated turbine disc alloys. Materials Science and Technology 2007; 23:1419-23.

[93] Padula Ii SA, Shyam A, Ritchie RO, Milligan WW. High frequency fatigue crack propagation behavior of a nickel-base turbine disk alloy. International Journal of Fatigue 1999;21:725-31.

[94] Wasén J, Heier E. Fatigue crack growth thresholds - the influence of Young's modulus and fracture surface roughness. International Journal of Fatigue 1998; 20:737-42.

[95] Krueger DD, Antolovich SD, Stone RHV. Effects of grain size and precipitate size on the fatigue crack growth behavior of alloy 718 at $427^{\circ} \mathrm{C}$. Metallurgical Transaction A 1987; 18:1431-49.

[96] Toh SF, Rainforth WM. Fatigue of a nickel base superalloy with bimodal grain size. Materials Science and Technology 1996; 12:1007-14.

[97] J. Telesman TPG, A. Garg, P. Bonacuse and J.Gayda. Effect of Microstructure on Time Dependent Fatigue Crack Growth Behavior in a P/M Turbine Disk Alloy. TMS Superalloys 2008, 2008:807-16.

[98] Zhang LN, Wang P, Dong JX, Zhang MC. Microstructures' effects on high temperature fatigue failure behavior of typical superalloys. Materials Science and Engineering: A 2013; 587:168-78.

[99] Telesman J, Gabb TP, Ghosn LJ. Separating the Influence of Environment from Stress Relaxation Effects on Dwell Fatigue Crack Growth in a Nickel-Base Disk Alloy. Superalloys 2016: John Wiley \& Sons, Inc.; 2016. p. 549-60.

[100] Knowles DM, Hunt DW. The influence of microstructure and environment on the crack growth behavior of powder metallurgy nickel superalloy RR1000. Metallurgical and Materials Transaction A 2002; 33:3165-72.

[101] Gabb TP, Kantzos PT, Telesman J, Gayda J, Sudbrack CK, Palsa B. Fatigue resistance of the grain size transition zone in a dual microstructure superalloy disk. International Journal of Fatigue 2011; 33:414-26.

[102] Hou J, Dong JX, Yao ZH, Jiang H, Zhang MC. Influences of PPB, PPB affect zone, grain boundary and phase boundary on crack propagation path for a P/M superalloy FGH4096. Materials Science and Engineering: A 2018; 724:17-28.

[103] Hou J, Dong JX. Characteristics of Microscopic Inclusions and their Influence on Fatigue Crack Propagation in FGH96 Superalloy. Materials Science Forum 2017; 898:505-16.

[104] Onofrio G, Osinkolu GA, Marchionni M. Fatigue crack growth of UDIMET 720 Li superalloy at 
elevated temperature. International Journal of Fatigue 2001; 23:887-95.

[105] Yang H, Bao R, Zhang J, Peng L, Fei B. Crack growth behaviour of a nickel-based powder metallurgy superalloy under elevated temperature. International Journal of Fatigue 2011; 33:632-41.

[106] Billot T, Villechaise P, Jouiad M, Mendez J. Creep-fatigue behavior at high temperature of a UDIMET 720 nickel-base superalloy. International Journal of Fatigue 2010; 32:824-9.

[107] Liu H, Bao R, Zhang J, Fei B. A creep-fatigue crack growth model containing temperature and interactive effects. International Journal of Fatigue 2014; 59:34-42.

[108] Starink MJ, Reed PAS. Thermal activation of fatigue crack growth: Analysing the mechanisms of fatigue crack propagation in superalloys. Materials Science and Engineering: A 2008; 491:279-89.

[109] Woodford DA. Gas phase embrittlement and time dependent cracking of nickel based superalloys. Energy Materials: Materials Science and Engineering for Energy Systems 2006; 1:59-79.

[110] Winstone MR, Nikbin KM, Webster GA. Modes of failure under creep/fatigue loading of a nickel-based superalloy. Journal of Material Sciences 1985; 20:2471-6.

[111] Ghonem H, Nicholas, T., Pineau, A. Elevated temperature fatigue crack growth in alloy 718-part I: effects of mechanical variables Fatigue \& Fracture of Engineering Materials \& Structures 1993; 16:565-76.

[112] Tong J, Dalby S, Byrne J. Crack growth in a new nickel-based superalloy at elevated temperature. Journal of Material Science 2005; 40:1237-43.

[113] Dalby S, Tong J. Crack growth in a new nickel-based superalloy at elevated temperature. Journal of Material Science 2005; 40:1217-28.

[114] Tong J, Byrne J. Effects of frequency on fatigue crack growth at elevated temperature. Fatigue \& Fracture of Engineering Materials \& Structures 1999; 22:185-93.

[115] Onofrio G, Osinkolu GA, Marchionni M. Effects of loading waveform on fatigue crack growth of Udimet 720 Li superalloy. International Journal of Fatigue 2004; 26:203-9.

[116] Yu SY, Li HY, Hardy MC, McDonald SA, Bowen P. Mechanisms of dwell fatigue crack growth in an advanced nickel disc alloy RR1000. MATEC Web of Conferences 2014; 14:03002.

[117] Adair BS, Johnson WS, Antolovich SD, Staroselsky A. Identification of fatigue crack growth mechanisms in IN100 superalloy as a function of temperature and frequency. Fatigue \& Fracture of Engineering Materials \& Structures 2013; 36:217-27.

[118] Xu C, Yao Z-H, Dong J-X, Jiang Y-K. Mechanism of high-temperature oxidation effects in fatigue crack propagation and fracture mode for FGH97 superalloy. Rare Metals 2019; 38:642-652

[119] Pretty CJ, Whittaker MT, Williams SJ. Crack Growth of a Polycrystalline Nickel Alloy under TMF Loading. Advanced Materials Research 2014; 891-892:1302-7.

[120] Jacques S, Lynch M, Wisbey A, Stekovic S, Williams S. Development of fatigue crack growth testing under thermo-mechanical fatigue conditions. Materials at High Temperatures 2013; 30:49-61.

[121] Jones J, Whittaker M, Lancaster R, Hyde C, Rouse J, Engel B, Pattison S, Stekovic S, Jackson C, Li HY, The effect of phase angle on crack growth mechanisms under thermo-mechanical fatigue loading. International Journal of Fatigue 2020; 135: 105539, https://doi.org/10.1016/j.ijfatigue.2020.105539.

[122] Molins R, Hochstetter G, Chassaigne JC, Andrieu E. Oxidation effects on the fatigue crack growth behaviour of alloy 718 at high temperature. Acta Materialia 1997; 45:663-74.

[123] Gayda J, Miner RV. Fatigue crack initiation and propagation in several nickel-base superalloys at $650^{\circ} \mathrm{C}$. International Journal of Fatigue 1983; 5:135-43.

[124] Kitaguchi HS, Moody MP, Li HY, Evans HE, Hardy MC, Lozano-Perez S. An atom probe 
tomography study of the oxide-metal interface of an oxide intrusion ahead of a crack in a polycrystalline Ni-based superalloy. Scripta Materialia 2015; 97:41-4.

[125] Viskari L, Hörnqvist M, Moore KL, Cao Y, Stiller K. Intergranular crack tip oxidation in a Ni-base superalloy. Acta Materialia 2013; 61:3630-9.

[126] Hörnqvist M, Viskari L, Moore KL, Stiller K. High-temperature crack growth in a Ni-base superalloy during sustained load. Materials Science and Engineering: A 2014; 609:131-40.

[127] Andrieu E, Molins R, Ghonem H, Pineau A. Intergranular crack tip oxidation mechanism in a nickel-based superalloy. Materials Science and Engineering: A 1992; 154:21-8.

[128] Karabela A, Zhao LG, Tong J, Simms NJ, Nicholls JR, Hardy MC. Effects of cyclic stress and temperature on oxidation damage of a nickel-based superalloy. Materials Science and Engineering: A 2011; 528:6194-202.

[129] Foss BJ, Hardy MC, Child DJ, McPhail DS, Shollock BA. Oxidation of a Commercial Nickel-Based Superalloy under Static Loading. Journal of the Minerals, Metals and Materials Society 2014; 66:2516-24.

[130] Viskari L, Johansson S, Stiller K. Oxygen influenced intergranular crack propagation: analysing microstructure and chemistry in the crack tip region. Materials at High Temperatures 2011; 28:336-41.

[131] Carroll JD, Abuzaid W, Lambros J, Sehitoglu H. High resolution digital image correlation measurements of strain accumulation in fatigue crack growth. International Journal of Fatigue 2013; 57:140-50.

[132] Lu YW, Lupton C, Zhu ML, Tong J. In Situ Experimental Study of Near-Tip Strain Evolution of Fatigue Cracks. Experimental Mechanics 2015; 55:1175-85.

[133] Krupp U, Wackermann K, Christ H-J, Colliander MH, Stiller K. Intergranular Oxidation Effects During Dwell-Time Fatigue of High-Strength Superalloys. Oxidation of Metals 2017; 88:3-14.

[134] Ma L, Chang K-M. Identification of SAGBO-induced damage zone ahead of crack tip to characterize sustained loading crack growth in alloy 783. Scripta Materialia 2003; 48:1271-6.

[135] Németh AAN, Crudden DJ, Armstrong DEJ, Collins DM, Li K, Wilkinson AJ, et al. Environmentally-assisted grain boundary attack as a mechanism of embrittlement in a nickel-based superalloy. Acta Materialia 2017; 126:361-71.

[136] Miller CF, Simmons GW, Wei RP. Evidence for internal oxidation during oxygen enhanced crack growth in P/M Ni-based superalloys. Scripta Materialia 2003; 48:103-8.

[137] Ghonem H, Zheng D. Depth of intergranular oxygen diffusion during environment-dependent fatigue crack growth in alloy 718. Materials Science and Engineering: A 1992; 150:151-60.

[138] Telesman J, Smith TM, Gabb TP, Ring AJ. An Abrupt Transition to an Intergranular Failure Mode in the Near-Threshold Fatigue Crack Growth Regime in Ni-Based Superalloys. Metallurgical and Material Transaction A 2018; 49:3838-53.

[139] Telesman J, Smith TM, Gabb TP, Ring AJ. Relationship between unusual high-temperature fatigue crack growth threshold behavior in superalloys and sudden failure mode transitions. Materials Science and Engineering: A 2017; 708:336-50.

[140] Ghonem H, Nicholas T, Pineau A. Elevated temperature fatigue crack growth in alloy 718 — part II: effects of environmental and material variables Fatigue \& Fracture of Engineering Materials \& Structures 1993; 16:577-90.

[141] Bing P, Kemao Q, Huimin X, Anand A. Two-dimensional digital image correlation for in-plane displacement and strain measurement: a review. Measurement Science and Technology 2009; 20:062001. 
[142] Di Gioacchino F, Quinta da Fonseca J. Plastic Strain Mapping with Sub-micron Resolution Using Digital Image Correlation. Experimental Mechanics 2013; 53:743-54.

[143] Di Gioacchino F, Quinta da Fonseca J. An experimental study of the polycrystalline plasticity of austenitic stainless steel. International Journal of Plasticity 2015; 74:92-109.

[144] Stinville JC, Echlin MP, Texier D, Bridier F, Bocher P, Pollock TM. Sub-Grain Scale Digital Image Correlation by Electron Microscopy for Polycrystalline Materials during Elastic and Plastic Deformation. Experimental Mechanics 2015:1-20.

[145] Stinville JC, Vanderesse N, Bridier F, Bocher P, Pollock TM. High resolution mapping of strain localization near twin boundaries in a nickel-based superalloy. Acta Materialia 2015; 98:29-42.

[146] Walley JL, Wheeler R, Uchic MD, Mills MJ. In-Situ Mechanical Testing for Characterizing Strain Localization During Deformation at Elevated Temperatures. Experimental Mechanics 2012; 52:405-16.

[147] Carter JLW, Kuper MW, Uchic MD, Mills MJ. Characterization of localized deformation near grain boundaries of superalloy René-104 at elevated temperature. Materials Science and Engineering: A 2014; 605:127-36.

[148] Kamaya M, Wilkinson AJ, Titchmarsh JM. Quantification of plastic strain of stainless steel and nickel alloy by electron backscatter diffraction. Acta Materialia 2006; 54:539-48.

[149] Wilkinson AJ, Meaden G, Dingley DJ. High-resolution elastic strain measurement from electron backscatter diffraction patterns: New levels of sensitivity. Ultramicroscopy 2006; 106:307-13.

[150] Carroll J, Abuzaid W, Lambros J, Sehitoglu H. On the interactions between strain accumulation, microstructure, and fatigue crack behavior. International Journal of Fracture 2013; 180:223-41.

[151] Tong J. Full-field characterisation of crack tip deformation and fatigue crack growth using digital image correlation - a review. Fatigue \& Fracture of Engineering Materials \& Structures 2018; 41:1855-69.

[152] Zhu ML, Lu YW, Lupton C, Tong J. In situ near-tip normal strain evolution of a growing fatigue crack. Fatigue \& Fracture of Engineering Materials \& Structures 2016; 39:950-5.

[153] Tong J, Lin B, Lu YW, Madi K, Tai YH, Yates JR, et al. Near-tip strain evolution under cyclic loading: In situ experimental observation and numerical modelling. International Journal of Fatigue 2015; 71:45-52.

[154] Norman V, Stekovic S, Jones J, Whittaker M, Grant B, On the mechanistic difference between in-phase and out-of-phase thermo-mechanical fatigue crack growth. International Journal of Fatigue 2020; 135: 105528, https://doi.org/10.1016/j.ijfatigue.2020.105528.

[155] Stekovic S, Jones JP, Engel B, Whittaker MT, Norman V, Rouse JP, Pattison S, Hyde CJ, Härnman P, Lancaster RJ, Leidermark D, Moverare J, DevTMF - Towards code of practice for thermo-mechanical fatigue crack growth. International Journal of Fatigue 2020; 138: 105675, https://doi.org/10.1016/j.ijfatigue.2020.105675.

[156] Palmer J, Jones J, Dyer A, Smith R, Lancaster R, Whittaker M. Development of test facilities for thermo-mechanical fatigue testing. International Journal of Fatigue 2019; 121:208-18.

[157] Olivier M.D.M. Messé JL, Andrew King, Jean Yves Buffière, Cathie M.F. Rae. Investigation of Fatigue Crack Propagation in Nickel Superalloy Using Diffraction Contrast Tomography and Phase Contrast Tomography. Advanced Materials Research 2014; 891:923-8. 